NOTICE: this is the author's version of a work that was accepted for publication in Geoderma. A definitive version was subsequently published in Geoderma 280, 29-37, 2016. http://dx.doi.org/10.1016/j.geoderma.2016.06.004

(C) 2016, Elsevier. Licensed under the Creative Commons Attribution-NonCommercial-NoDerivatives 4.0 International http://creativecommons.org/licenses/by-nc-nd/4.0.

\title{
Evolution of phosphorus speciation with depth in an agricultural soil profile
}

\author{
Ann Kristin Eriksson ${ }^{\mathrm{a},{ }^{*}}$, Stephen Hillier ${ }^{\mathrm{a}, \mathrm{b}}$, Dean Hesterberg ${ }^{\mathrm{c}}$, Wantana Klysubun ${ }^{\mathrm{d}}$, Barbro Ulén ${ }^{\mathrm{a}}$ \\ and Jon Petter Gustafsson ${ }^{\mathrm{a}, \mathrm{e}}$ \\ ${ }^{a}$ Department of Soil and Environment, Swedish University of Agricultural Sciences, P.O. Box 7014, SE- \\ 75007, Uppsala, Sweden. \\ ${ }^{b}$ The James Hutton Institute, Craigiebuckler, Aberdeen, AB15 8QH, United Kingdom \\ ${ }^{c}$ Department of Soil Science, North Carolina State University, Box 7619, Raleigh, NC 27695-7619, U.S. \\ ${ }^{d}$ Synchrotron Light Research Institute (SLRI), 111 University Avenue, Muang District, Nakhon \\ Ratchasima 30000, Thailand \\ ${ }^{e}$ Division of Land and Water Resources Engineering, KTH Royal Institute of Technology, Teknikringen \\ 76, 10044 Stockholm, Sweden.
}

*Corresponding author: Ann Kristin Eriksson

e-mail: ann.kristin.eriksson@slu.se

phone: +4618 671243 


\begin{abstract}
With time, different soil-forming processes such as weathering, plant growth, accumulation of organic matter, and cultivation are likely to affect phosphorus (P) speciation. In this study, the depth distribution of P species was investigated for an agricultural clay soil, Lanna, Sweden. Small amounts of apatite-P was demonstrated in the topsoil whereas the speciation of $\mathrm{P}$ at 70-100 cm depth consisted of approximately $86 \%$ apatite according to P K-edge XANES (X-ray absorption near-edge structure) spectroscopy. Because there were only minor differences in bulk mineralogy and texture, these variations in $\mathrm{P}$ speciation were interpreted as the result of apatite weathering of the topsoil. Speciation modeling on soil extracts supported this idea:

hydroxyapatite was not thermodynamically stable in the top $50 \mathrm{~cm}$ of the soil. Apatite was enriched in the bulk soil relative to the clay fraction, as expected during apatite dissolution. Combined results from batch experiments, XANES spectroscopy and X-ray diffraction suggested chemical transformations of the topsoil as a result from accumulation of organic matter and airing from tillage followed by enhanced weathering of apatite, amphiboles, clay minerals, and iron oxides. This caused the formation of poorly crystalline secondary iron and aluminum (hydr)oxides in the topsoil, which retained part of the released P from apatite. Other P was incorporated into organic forms. Furthermore, the results also showed that short-term acidification below the current pH value (below 5.5 in the topsoil and 7.2 in the deeper subsoil) caused significant solubilization of $\mathrm{P}$. This is attributed to two different mechanisms: the instability of Al-containing sorbents (e.g. Al hydroxides) at low pH (in the topsoil), and the acidmediated dissolution of apatite (the subsoil).
\end{abstract}

Keywords: Acidification, Apatite, Clay, Secondary iron and aluminum (hydr)oxides, X-ray adsorption spectroscopy 


\section{Introduction}

The chemistry of phosphorus (P) in agricultural soils is of high relevance both due to its importance as a macronutrient, and to the risk of P leaching to surface waters where it may promote eutrophication (Bergström et al., 2015). Several factors determine the plant availability of $\mathrm{P}$ in soils and the risk of leaching; the $\mathrm{pH}$ value is one important factor. The $\mathrm{pH}$ value determines the extent of sorption to oxide surfaces as well as the solubility of calcium (Ca) phosphates. However, the impact of the $\mathrm{pH}$ value is complex and may result in different $\mathrm{pH}$ dependent P solubility relationships in different soils (Gustafsson et al., 2012). In non-calcareous clay soils, where iron ( $\mathrm{Fe}$ ) and aluminum ( $\mathrm{Al}$ ) (hydr)ous oxides are likely to have a significant role for P dynamics (Eriksson et al., 2015), the solubility of inorganic orthophosphate $\left(\mathrm{PO}_{4}\right)$ ions (e.g. $\mathrm{H}_{2} \mathrm{PO}_{4}{ }^{-}, \mathrm{HPO}_{4}{ }^{2-}$ ) is lowest at $\mathrm{pH} 6$ to 7 (Gustafsson et al., 2012; Weng et al., 2011), and increases with decreasing $\mathrm{pH}$. This result is not the expected one for soils rich in oxide mineral surfaces, as $\mathrm{P}$ adsorption on pure oxide minerals typically decreases with increasing $\mathrm{pH}$ due to lower positive surface charge of oxides (see e.g. Goldberg and Sposito, 1984). The instability and dissolution of Al-containing sorbents at low $\mathrm{pH}$ may explain the observed $\mathrm{pH}$ dependence (Gustafsson et al., 2012). Alternatively, a more extensive dissolution of Ca phosphates at lower pH may cause the observed pH dependence (Hartikainen and Simojoki, 1997). As far back as in the 1950, Mattson et al. found that in the clay soil from the Lanna experimental farm, Sweden, the solubility of phosphate $\left(\mathrm{PO}_{4}\right)$ increased rapidly with decreasing $\mathrm{pH}$. This trend was most pronounced in the subsoil and the authors hypothesized that Ca phosphates present in the subsoil dissolved at lower $\mathrm{pH}$. However, the $\mathrm{P}$ release from soil is not only important in the short time term; it also may be a key element in pedogenesis (Walker and Syers, 1976). For these reasons, a large body of recent research has explored the speciation and solubility of P in agricultural soils (e.g. Beauchemin et al., 2003; Gustafsson et al., 2012; Weng et al., 2011). Beauchemin et al. (2003) demonstrated that Ca phosphates were present in five diverse soils, regardless of $\mathrm{pH}$, between 5.5 and 7.6. The presence of Ca phosphate was also suggested for a clay soil with a history of high loads of manure P (Ulén \& Snäll, 2008). Furthermore, soils containing hydroxy polymers in the interlayer area of clay minerals have shown increased affinity of P sorption (Karathanasis \& Shumaker, 2009). In addition, other clay minerals such as kaolinite, montmorillonite and illite may be of importance for P sorption (Manning and Goldberg, 1996). 
Information on $\mathrm{P}$ speciation is required to understand both fast and slow processes that make $\mathrm{P}$ available for plants and to determine the extent of P mobilization. X-ray absorption near edge structure (XANES) spectroscopy is one available tool (e.g. Beauchemin et al., 2003; Hesterberg et al., 1999; Khare et al., 2004). Using XANES spectroscopy, it is possible to differentiate between different phosphate minerals and $\mathrm{P}$ adsorbed on oxide surfaces depending on the features of the XANES spectrum: (1) iron(III)-bound phosphate shows a distinct pre-edge peak; (2) calcium phosphates show post-edge shoulders that are unique for different calcium phosphate minerals; (3) organic phosphorus species have a broad white line peak, and; (4) adsorbed P commonly has a high white-line intensity (e.g. Franke and Hormes, 1995; Hesterberg et al., 1999). Additionally, valuable input to the understanding of $P$ sorption may be provided from an analysis of the mineralogical composition of the soil.

The aim of this study was to investigate the speciation and solubility of $\mathrm{P}$ in a profile from a typical agricultural soil (Lanna) in southern Sweden, where earlier research has indicated contrasting P speciation and extractability within the pedon (Andersson et al., 2015; Mattson et al., 1950). Combined information on speciation (XANES spectroscopy), pH-dependent solubility (batch experiments), mineralogical analysis (X-ray diffraction), and speciation modelling, was used to identify important chemical processes influencing $\mathrm{P}$ availability and leaching.

\section{Materials and methods}

\subsection{The Lanna experimental farm}

Lanna is an experimental farm situated in the largest agricultural plain of southwestern Sweden $\left(58^{\circ} 21^{\prime} \mathrm{N} 13^{\circ} 07^{\prime} \mathrm{E}\right)$. The sampled soil is representative of the soil type commonly found on this plain (Johansson, 1944). During the last 12 years before sample collection perennial forage crops were grown at the site, and no fertilizers were added at the location where the samples were collected (Andersson et al., 2015; Andersson et al., 2013). The soil is classified as an Udertic Haploboroll with a silty clay topsoil and a clay subsoil both with strong coarse subangular blocky structure (Bergström et al., 1994). The mean annual temperature is $6{ }^{\circ} \mathrm{C}$ and the precipitation is $560 \mathrm{~mm}$. The farm, which is artificially drained, was established in 1929 and several studies regarding $\mathrm{P}$ in soils have been made at this site. Examples include effects of liming on soil $\mathrm{P}$ (Mattson et al., 1950), the influence of different soil management practices on P losses (Aronsson 
et al., 2011), cropping systems (Neumann et al., 2011), and the role of the subsoil in affecting $P$ losses (Andersson et al., 2015; Andersson et al., 2013).

\subsection{General soil characterisation}

The soil used was sampled for the investigations made by Andersson et al. (2013; 2015). Soil samples were collected from a profile at 0-10, 10-30, 30-50, 50-70 and 70-100 cm depth. Samples for each depth were taken from 5 locations at the site (within a ditch of $10 \mathrm{~m}$ length). The samples were air-dried at approximately $30^{\circ} \mathrm{C}$ and sieved $(<2 \mathrm{~mm})$. These soils from glacial clay deposits contain no coarse fragments $>2 \mathrm{~mm}$. In this study the samples from the 5 locations at each depth were mixed into one bulk sample with approximately the same amount of soil from each location. Clay fractions ( $<2 \mu \mathrm{m}$, equivalent spherical diameter) were separated from the soils by sedimentation according to Stokes' law, as described in Eriksson et al. (2015). The isolation may affect the P speciation, but the effects seem small (Eriksson et al. 2015). The texture was determined after sieving and sedimentation by the pipette method according to ISO 11277 (2009). The pH was measured after suspending $6 \mathrm{~g}$ soil in $18 \mathrm{~cm}^{3} \mathrm{H}_{2} \mathrm{O}$. Pseudo-total $\mathrm{P}$ was digested with a method modified from ISO 11466 (1995), in which $3 \mathrm{~g}$ of dry soil was equilibrated with $30 \mathrm{~cm}^{3}$ aqua regia solution for $16 \mathrm{~h}$. The suspension was then boiled for $2 \mathrm{~h}$ and connected to a water condenser to minimize evaporation. After digestion, the suspension was filtered and diluted to $100 \mathrm{~cm}^{3}$ with $0.5 \mathrm{M} \mathrm{HNO}_{3}$. Phosphorus was determined by ICP-OES using a Perkin Elmer 5300 DV instrument. Phosphorus was also digested in $\mathrm{HCl}$ by boiling $2 \mathrm{~g}$ of dry soil in $50 \mathrm{~cm}^{3} 2 \mathrm{M} \mathrm{HCl}$ for $2 \mathrm{~h}$ (KLS, 1965). The suspension was filtered and analysed by ICPOES. Oxalate (ox)-extractable Al, Fe and $\mathrm{PO}_{4}$ were determined according to van Reeuwijk (1995): $1 \mathrm{~g}$ dry soil and $100 \mathrm{~cm}^{3} 0.2 \mathrm{M}$ oxalate buffer ( $\mathrm{pH}$ 3.0) was equilibrated for $4 \mathrm{~h}$ in darkness. The extract was then filtered through a $0.2 \mu \mathrm{m}$ single-use filter and diluted 1:5 in $\mathrm{H}_{2} \mathrm{O}$. The concentrations of $\mathrm{Al}$ and $\mathrm{Fe}$ in the extract were analysed by ICP-OES (Inductively coupled plasma optical emission spectroscopy) using an ICP Optima 7300 DV instrument. The concentration of $\mathrm{PO}_{4}$ in the oxalate extract $\left(\mathrm{PO}_{4}-\mathrm{Ox}\right)$ was determined (acid molybdate method modified by Wolf and Baker, 1990) using a Tecator Aquatec 5400 spectrophotometer. Pyrophosphate-extractable $\mathrm{Al}$ and Fe were extracted by shaking $1 \mathrm{~g}$ of soil with $0.1 \mathrm{M} \mathrm{Na}$ pyrophosphate for $16 \mathrm{~h}$. The extract was then filtered through a $0.2 \mu \mathrm{m}$ Acrodisc PF single-use filter and diluted 1:5 in $\mathrm{H}_{2} \mathrm{O}$ before analysis by ICP-OES. Phosphorus was also extracted by acid 
ammonium lactate (P-AL) according to the method of Egnér et al. (1960): 5 g soil was shaken for $1.5 \mathrm{~h}$ with a solution containing $0.1 \mathrm{M}$ ammonium lactate and $0.4 \mathrm{M}$ acetic acid, with a $\mathrm{pH}$ adjusted to 3.75. The suspension was filtered $(0.2 \mu \mathrm{m})$ before analysis by ICP-OES. The total organic carbon content was measured by combustion using a LECO CNS-2000 analyzer LECO, St. Joseph, MI.

\subsection{Bulk mineralogy}

The samples ( $<2 \mathrm{~mm}$ ) were micronized in ethanol $\left(10 \mathrm{~cm}^{3}\right.$ to $3 \mathrm{~g}$ soil) with a McCrone mill, and a random powder was formed by spray drying of the slurry (Hillier, 1999). These random powders were packed into metal holders and diffraction patterns were recorded using a Philips Xpert Pro diffractometer using $\mathrm{Ni}$ filtered $\mathrm{Cu} \mathrm{K} \alpha$ radiation. X-ray diffraction (XRD) patterns were recorded from $2 \theta=3^{\circ}$ to $70^{\circ}$ by scanning in $0.0167^{\circ}$ steps and counting for 300 s per step. The patterns were quantitatively analysed with full pattern fitting according to the method outlined in Omotoso et al. (2006). Clay minerals/phyllosilicates used in the fitting were vermiculite, biotite, hydrobiotite, chlorite, illite, muscovite, kaolinite and various mica/smectite mixed-layer minerals.

\subsection{Clay mineralogy}

Orientated clay mineral samples were prepared by transferring $<2 \mu \mathrm{m}$ clay suspensions to glass slides by the filter peel transfer method (Moore and Reynolds, 1997). X-ray diffraction patterns were recorded on a Siemens D5000 diffractometer using Fe-filtered Co K $\alpha$ radiation after air drying, after ethylene glycol vapor solvation at $60^{\circ} \mathrm{C}$ overnight and after heating to $300^{\circ} \mathrm{C}$ for $1 \mathrm{~h}$ on a hot plate. All patterns were recorded from $2 \theta=2^{\circ}$ to $45^{\circ}$ by scanning in $0.02^{\circ}$ steps and counting for $1 \mathrm{~s}$ per step. Subsamples were also run in an identical set of treatments following $\mathrm{K}^{+}$ saturation. $\mathrm{K}^{+}$saturation was made by adding $20 \mathrm{~mL} 1 \mathrm{M} \mathrm{KCl}$ to approximately $100 \mathrm{mg}$ of clay and left overnight. The samples were then collected by filtration through $0.45 \mu \mathrm{m}$ filters, and rinsed twice by passing two further $20 \mathrm{~mL}$ volumes of $1 \mathrm{M} \mathrm{KCl}$ through the sample. Residual salt was removed by passing three portions of $20 \mathrm{~mL}$ of deionized water through the filter.

Semi-quantitative X-ray diffraction analysis was performed with the peak area-based reference intensity ratio (RIR) method (Hillier, 2003) using the EVA DIFFRAC ${ }^{\text {plus }}$ software (Bruker, 2005). Calculations for different minerals were based on RIRs calculated with NEWMOD ${ }^{\complement}$ 
(Reynolds, 1985). With the scanning conditions employed, detection limits for crystalline minerals are nominally some fraction of 1 wt.\% (Hillier, 2003). The amount of hydroxyinterlayering was measured according to Eriksson (2016), in which the center of gravity (COG) was determined for the XRD pattern between 9.5 and $15.5 \AA$ after K-saturation and heating to $300{ }^{\circ} \mathrm{C}$ on a hot plate.

\subsection{P K-edge XANES spectroscopy and data analysis}

Phosphorus K-edge XANES spectra were collected at beam line BL8 (Klysubun et al., 2012) at the Synchrotron Light Research Institute (SLRI) in Nakhon Ratchasima, Thailand. Prior to XANES analysis, the samples were milled and sieved $(<0.05 \mathrm{~mm})$ to minimize self-absorption effects. The soil samples were packed into $2 \mathrm{~mm}$ thick stainless steel holders $(1 \mathrm{x} 1.5 \mathrm{~cm}$ with a sample window of $0.5 \times 1 \mathrm{~cm}$ ) and covered with polypropylene film. The clay fractions were mounted on P-free Kapton tape. The beamline was equipped with an InSb (111) crystal monochromator and a beam flux of $1.3 \times 10^{9}$ to $6 \times 10^{10}$ photons s$^{-1}(100 \mathrm{~mA})^{-1}$ for the investigated energy range. The size of the beam was 12.5 x $0.9 \mathrm{~mm}$ and data were collected using a solid state 13-element Ge fluorescence detector. To minimize X-ray absorption by air, the sample compartment was filled with helium gas. Spectra of samples and standards were recorded across an energy range from 2100 to $2320 \mathrm{eV}$. The step size was $2 \mathrm{eV}$ between 2100 and 2132 $\mathrm{eV}, 1 \mathrm{eV}$ between 2132 and $2144 \mathrm{eV}, 0.2 \mathrm{eV}$ between 2144 and $2153 \mathrm{eV}, 0.3 \mathrm{eV}$ between 2153 and $2182 \mathrm{eV}$, and $5 \mathrm{eV}$ between 2182 and $2320 \mathrm{eV}$. All measurements were recorded using a dwell time of 3 s per energy step.

The XANES analysis of standards, soil samples and clay fractions were performed using the Athena software, version 0.9.020 (Ravel and Newville, 2005). Merged spectra were normalized using the following procedure: a linear baseline function was subtracted from the spectral region below the edge (between -30 to $-10 \mathrm{eV}$ relative to $\mathrm{E}_{0}$ ), and normalized to unit edge step and quadrature removed across the post-white-line region (between 30 and $45 \mathrm{eV}$ relative to $\mathrm{E}_{0}$ ). Linear combination fitting (LCF) analysis (Tannazi and Bunker, 2005) was done using weighted combinations of spectra from 30 known standards (see Supplementary data, Fig. S1) to fit the sample spectra. All standards used in the evaluation were characterized by X-ray diffraction, and XANES data were collected at the same beamline as the samples (see Supplementary data, Fig. 
S1 and S2 for XANES spectra, and Table S1 for the composition of the natural apatites). No energy shifts were permitted in the fitting procedure. At most three standards were accepted in each fit and the fitting range was constrained to between -10 to $30 \mathrm{eV}$ relative to $\mathrm{E}_{0}$. Only fits within $\pm 10 \%$ of the sample (set to $100 \%$ ) were accepted and re-normalized to $100 \%$. Because the XANES spectra of P adsorbed on different Fe (hydr)oxides (goethite and ferrihydrite) are rather similar, the fractions obtained by LCF were summed to give the P adsorbed on Fe (hydr)oxides. Similarly, the $\mathrm{P}$ adsorbed on gibbsite and amorphous Al hydroxide were summed to give $\mathrm{P}$ adsorbed on $\mathrm{Al}$ (hydr)oxides. For samples in which calcium phosphates were included, the fit was constrained to include only one calcium phosphate phase. Since the Taiba natural apatite was most commonly selected by this procedure, all samples were refit with only the Taiba apatite as a calcium phosphate standard. These procedures caused only a minor increase in the misfit factor (R-factor). The R-factor is calculated according to Ravel (2009) and should be seen as a statistical estimate of the goodness-of-fit.

Each estimated contribution in the LCF analysis is accompanied by an estimate of the statistical uncertainty as calculated by Athena (Ravel and Newville, 2005). It is important to recognize that these uncertainties do not consider uncertainties during background subtraction and normalization (Ajiboye et al., 2007; 2008). Therefore, the real uncertainty of an LCF is larger, as shown by studies in which the P speciation of well-defined mixtures was calculated by LCF (Ajiboye et al., 2007; Werner and Prietzel, 2015). However, consideration of normalization errors is difficult for samples with unknown composition. For example, this would require a priori assumptions on the probability of different sets of normalization parameters, an issue that is not well explored.

\subsection{Solubility experiments}

For the batch experiments, 2 g dry soil were suspended in $30 \mathrm{~cm}^{3}$ solution of varying composition (c.f. below) for $7 \mathrm{~d}$ in darkness at $22^{\circ} \mathrm{C}$. The suspensions were shaken in polypropylene centrifuge tubes with screw caps. All suspensions contained $0.01 \mathrm{M} \mathrm{NaNO}_{3}$ as a background electrolyte. Varying concentrations of acid $\left(\mathrm{as}_{\mathrm{HNO}_{3}}\right)$ or base (as $\left.\mathrm{NaOH}\right)$ were added to produce a range of $\mathrm{pH}$ values. The acid treatments contained 5, 4, 3, 2 and $1 \mathrm{mM}$ of $\mathrm{HNO}_{3}$ and the base treatment contained 1 and $2 \mathrm{mM}$ of $\mathrm{NaOH}$. All treatments were applied in duplicate. After $7 \mathrm{~d}$ of 
reaction, the samples were centrifuged in $3000 \mathrm{rpm}$ for $20 \mathrm{~min}$. The $\mathrm{pH}$ of the supernatant was measured using a Radiometer PHM93 reference $\mathrm{pH}$ meter with a GK2401C combined $\mathrm{pH}$ electrode. The remaining supernatant solution was filtered through a $0.2 \mu \mathrm{m}$ single use filter (Acrodisc PF) prior to the analysis of orthophosphate phosphorus ( $\mathrm{PO}_{4}-\mathrm{P}$; colorimetrically using a Tecator Aquatec 5400 spectrophotometer with flow injection analysis) and of $\mathrm{Ca}, \mathrm{Al}$ and $\mathrm{Fe}$ on ICP-OES as above.

Visual MINTEQ, ver. 3.1 (Gustafsson, 2014) was used for speciation modelling to calculate the activities of free $\mathrm{Ca}^{2+}, \mathrm{Al}^{3+}, \mathrm{Fe}^{3+}$ and $\mathrm{PO}_{4}-\mathrm{P}$ in solution. The solubility constants of various $\mathrm{Ca}-\mathrm{P}$, Al-P and Fe-P phases were those used by Gustafsson et al. (2012). All statistical analyses were carried out using MINITAB 16 Statistical Software.

\section{Results}

\subsection{Soil characteristics}

General soil characteristics are presented in Table 1 (composite sample of 5 subsamples). Both the clay content and $\mathrm{pH}$ increased with depth. The $\mathrm{pH}$ was 6.1 in the upper $10 \mathrm{~cm}$ of the topsoil. The $\mathrm{pH}$ in the subsoil ranged from 6.8 at $30-50 \mathrm{~cm}$ depth to 7.2 at $70-100 \mathrm{~cm}$. The clay content (< $2 \mu \mathrm{m}$ ) was between 43 and $45 \%$ in the topsoil, but ranged between 56 and $61 \%$ in the subsoil. The organic $\mathrm{C}$ content was higher in the topsoil, ranging between 2.11 and $2.61 \%$, than in the subsoil, ranging between 0.16 and $0.44 \%$. The amount of oxalate-extractable $\mathrm{Al}$ was more or less constant throughout the profile (63.4-68.6 mmol kg-1), but a larger amount of pyrophosphateextractable Al was found in the topsoil (10.7-11.9 mmol kg${ }^{-1}$ ) compared to the subsoil (2.6-5.6 mmol $\mathrm{kg}^{-1}$ ). By contrast, the amount of oxalate-extractable Fe decreased with increasing depth. The pseudo-total P concentration showed only small variations with depth, with the highest amount in the subsoil (Table 1), whilst extractable P forms (in particular P-AL and oxalate-P) increased substantially with depth.

\subsection{Mineralogy}

Between 60 and $70 \%$ of the bulk soil consisted of quartz, plagioclase and K-feldspar (Table 2; diffractograms in Supplementary data, Fig. S3), with an additional significant proportion of 
phyllosilicate clay minerals (between 21 and 28 \%) split approximately equally between dioctahedral and triocathedral types. Smaller contributions of amphibole and Fe oxide made up most of the remaining 5 to $7 \%$. No dramatic differences in mineralogy were found between the soil horizons; however, a higher proportion of quartz was found in the topsoil, and a greater proportion of clay minerals in the subsoil, there are also slightly greater amounts of amphibole and iron oxides found in the subsoil. As reported previously (Andersson et al., 2015; Andersson et al., 2013), our diffraction data showed no presence of carbonates, even in the alkaline samples.

Table 1: General soil characteristics ${ }^{\mathrm{a}}$

\begin{tabular}{|c|c|c|c|c|c|c|c|c|c|c|c|c|}
\hline Depth & Texture & Clay & pH & OrgC & Al-ox & Al-py & Fe-ox & Fe-py & P-AL & $\mathbf{P O}_{4^{-}-\mathrm{OX}}$ & P-HCl & P-Pstot \\
\hline & & (\%) & & (\%) & \multicolumn{8}{|c|}{$\left(\mathrm{mmol} \mathrm{kg}{ }^{-1}\right)$} \\
\hline $0-10 \mathrm{~cm}$ & Sc & 43 & 6.1 & 2.61 & 68.6 & 11.9 & 71.4 & 21.1 & 1.3 & 6.5 & 15.2 & 21.0 \\
\hline $10-30 \mathrm{~cm}$ & Sc & 45 & 6.4 & 2.11 & 63.7 & 10.7 & 63.6 & 18.4 & 1.3 & 6.5 & 12.9 & 19.4 \\
\hline $30-50 \mathrm{~cm}$ & C & 56 & 6.8 & 0.44 & 67.1 & 5.6 & 52.6 & 5.6 & 2.6 & 8.1 & 13.6 & 19.4 \\
\hline $50-70 \mathrm{~cm}$ & C & 58 & 7.0 & 0.20 & 65.6 & 3.7 & 51.4 & 2.0 & 6.5 & 16.1 & 18.1 & 24.5 \\
\hline $70-100 \mathrm{~cm}$ & C & 61 & 7.2 & 0.16 & 63.4 & 2.6 & 38.5 & 1.4 & 8.1 & 16.8 & 19.0 & 25.2 \\
\hline
\end{tabular}

${ }^{\mathrm{a}}$ Abbreviations: sc and c are silty clay and clay; Al-ox, Fe-ox and P-ox are Al, Fe and $\mathrm{PO}_{4}$ extracted by oxalate; Alpy and Fe-py are Al and Fe extracted by pyrophosphate; P-AL, P-HCl and P-Pstot are P extracted by acid ammonium lactate, $\mathrm{HCl}$ and digested by aqua regia, respectively.

Table 2: Bulk soil mineralogy as evidenced by X-ray diffraction.

\begin{tabular}{lcccccc}
\hline \multirow{2}{*}{ Depth } & Quartz & $\begin{array}{c}\text { Plagio- } \\
\text { clase }\end{array}$ & K-feldspar & Amphibole & $\begin{array}{c}\text { Iron } \\
\text { oxides }\end{array}$ & Clay minerals \\
\cline { 2 - 7 } & & 22 & 20 & 1.9 & 2.3 & 23 \\
\hline $0-10 \mathrm{~cm}$ & 31 & 22 & 20 & 1.8 & 2.4 & 24 \\
$10-30 \mathrm{~cm}$ & 30 & 22 & 19 & 1.9 & 3.0 & 33 \\
$30-50 \mathrm{~cm}$ & 21 & 23 & 20 & 2.3 & 3.1 & 31 \\
$50-70 \mathrm{~cm}$ & 21 & 23 & 19 & 2.5 & 2.7 & 31 \\
$70-100 \mathrm{~cm}$ & 22 & & & & & \\
\hline
\end{tabular}

Concerning the clay fraction (Table 3; diffractograms in Supplementary data, Fig. S4-S7), a relatively large fraction of mica/illite was found in the topsoil, whereas expandable minerals were somewhat enriched in the subsoil. The expandable minerals show various spacings in the glycolated traces of around 16,14, and $12 \AA$, all of which collapse to $10 \AA$ in the heated traces of the subsoil samples. $\mathrm{K}^{+}$saturation also resulted in complete collapse of the expandable minerals 
in subsoil samples. The various expanded spacings seen in glycolated traces are interpreted as low charge vermiculite (16 $\AA$ ) high charge vermiculite (14 $\AA$ ) and interstratified mica/vermiculite (12 $\AA$ ). When comparing the center of gravity (COG) for the K-saturated and heated samples, measured as a d-spacing ( $\AA$ ), the COG was greater in the topsoil, also consistent with a greater degree of interlayering than in the subsoil (Eriksson, 2016). Small amounts of kaolinite were detected in the clay fraction and in the whole profile, particularly in the surface samples, but no chlorite was identified. Overall the clay-size fractions also contain considerable amounts of quartz and feldspar, which is consistent with the large difference between the amount of clay minerals (according to XRD) and the clay content (Table 1 and Table 2).

Table 3: Clay mineralogy as evidenced by $\mathrm{X}$-ray diffraction. The center of gravity was calculated according to Eriksson (2016) as an indicator of the amount of hydroxy-interlayers.

\begin{tabular}{lccccc}
\hline Depth & Kaolinite & Chlorite & $\begin{array}{c}\text { Mica/ } \\
\text { illite }\end{array}$ & $\begin{array}{c}\text { Expandable } \\
\text { minerals }\end{array}$ & $\begin{array}{c}\text { Centre of gravity } \\
\text { K-sat } \mathbf{3 0 0}{ }^{\circ} \mathbf{C}\end{array}$ \\
\cline { 2 - 6 } & & \multicolumn{2}{c}{$(\%)$} & & $(\AA)$ \\
\hline $0-10 \mathrm{~cm}$ & 2 & n.d. & 23 & 75 & 10.5 \\
$10-30 \mathrm{~cm}$ & 3 & n.d. & 21 & 76 & 10.4 \\
$30-50 \mathrm{~cm}$ & 2 & n.d. & 17 & 81 & 10.2 \\
$50-70 \mathrm{~cm}$ & 3 & n.d. & 14 & 83 & 10.2 \\
$70-100 \mathrm{~cm}$ & 3 & n.d. & 16 & 81 & 10.2 \\
\hline
\end{tabular}

\subsection{Speciation of $P$ in soils by XANES spectroscopy}

The XANES spectra showed substantial differences in the P speciation in the pedon, as shown by changes in the spectral features and differences in linear combination fitting (LCF) results with depth (Fig. 1 and Table 4). Based on XANES spectra for standards giving the best fit to sample spectra, the speciation of $\mathrm{P}$ in the $0-10$ and 10-30 cm appears to be dominated by $\mathrm{P}$ adsorbed on $\mathrm{Al}$ (hydr)oxides, with an additional major contribution from organic diester P (fit as lecithin). The fact that the LCF procedure generated better fits for lecithin than for the other organic P standard, phytate, may possibly indicate a predominance of diester linkages in the organic P pool. It should be mentioned, however, that the spectra for organic P species are relatively featureless (Beauchemin et al. 2003), and consequently the discrimination between different organic $\mathrm{P}$ species is uncertain. Deeper down in the soil profile there was a pronounced increase in the 
proportion of calcium phosphate as apatite. The proportion of apatite increased from $15 \%$ in the 0-10 cm surface soil to $86 \%$ of total P in the $70-100 \mathrm{~cm}$ horizon. Contributions to the fits from organic $\mathrm{P}$ and $\mathrm{P}$ adsorbed on Fe (hydr)oxides were not found for the subsoil samples deeper than $30 \mathrm{~cm}$, whereas the proportion of $\mathrm{P}$ adsorbed to $\mathrm{Al}$ (hydr)oxide in the fits decreased with depth, from $55 \%$ of total P in the surface layer to $14 \%$ at $70-100 \mathrm{~cm}$.
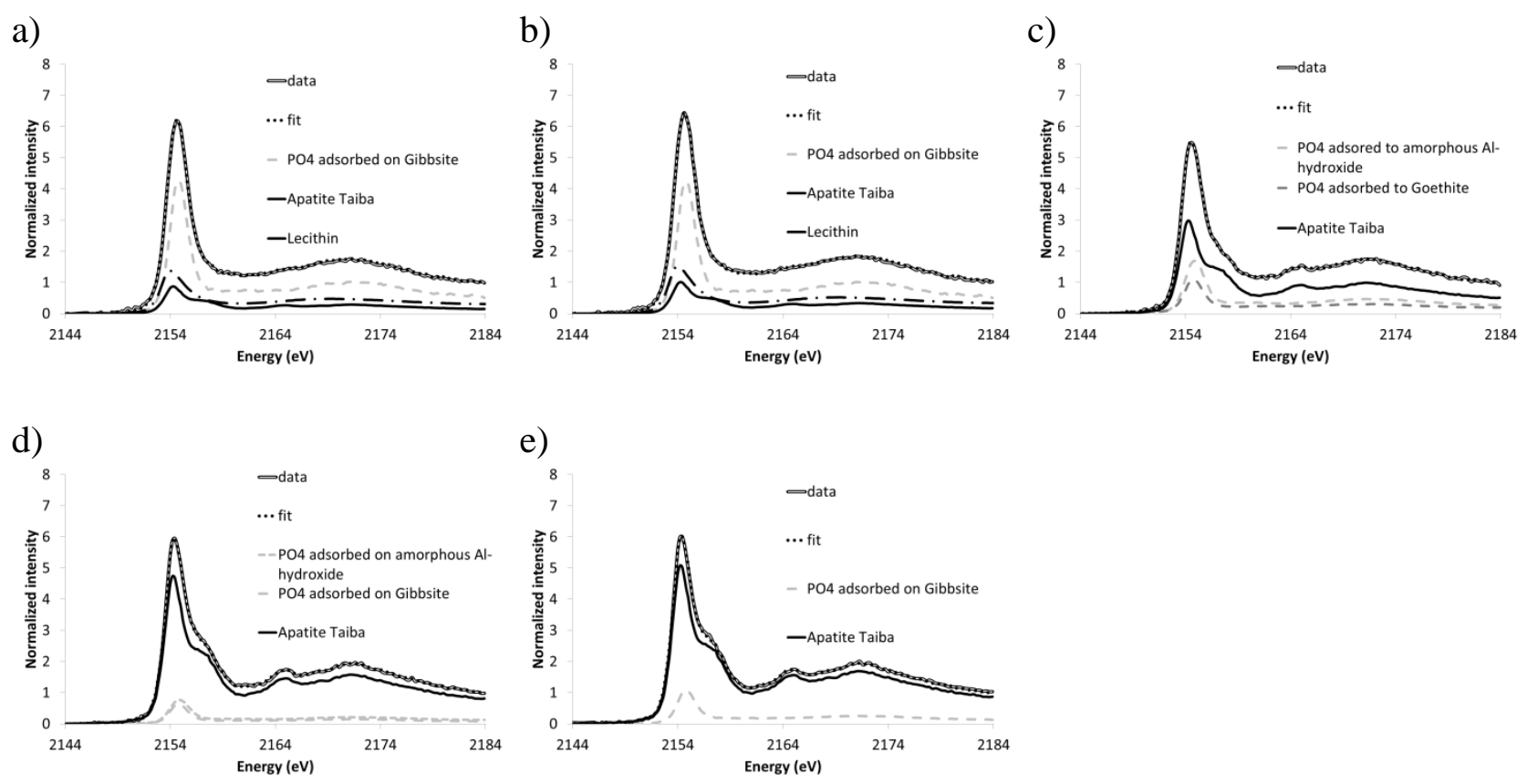

Fig. 1. Linear combination fitting of XANES spectra of the bulk soils. The grey solid line shows the measured data, and the dotted line is the linear combination fit. a) Lanna 0-10 cm b) Lanna 10-30 cm c) Lanna 30-50cm d) Lanna 50-70 cm and e) Lanna 70-100 cm.

The XANES spectra for the clay fractions showed similar trends, although the fractions of total P fit by the same standards varied (Table 4). Also, to evaluate any differences in P speciation between the bulk soil and clay fraction of the different soil horizons, LCFs were made for the bulk soil using the result from the clay fraction as a mandatory standard (Table 5), and with one additional permitted standard. For the topsoil (0-10 and 10-30 cm horizons) the best fits were obtained when the speciation in the clay fraction was combined with $\mathrm{P}$ adsorbed on $\mathrm{Al}$ (hydr)oxides. This was also not unexpected given the greater contribution of P adsorbed on these (hydr)oxides in fits for the bulk soil compared with the clay fraction (Table 4). This result 
suggests that the Fe (hydr)oxide-bound $\mathrm{P}$ and the organic $\mathrm{P}$, which made up most of the remaining fit, were more enriched than $\mathrm{Al}$ (hydr)oxide-bound $\mathrm{P}$ in the clay fraction. In the subsoil, however, apatite was more enriched in the bulk soil compared to $\mathrm{P}$ bound to $\mathrm{Al}$ (hydr)oxide.

Table 4: Phosphorus speciation in bulk soils and clay fractions as evidenced from linear combination fitting of XANES spectra. ${ }^{a}$ The R-factor is the goodness-of-fit parameter reported by Athena. Compounds in the five best fits are numbered in italics from 1 to 5 .

\begin{tabular}{|c|c|c|c|c|c|c|c|c|}
\hline & & $\begin{array}{l}\mathrm{P} \text { adsorbed on } \\
\text { Al hydroxide }\end{array}$ & $\begin{array}{l}\mathrm{P} \text { adsorbed on } \\
\text { Fe (hydr)oxide }\end{array}$ & $\mathrm{AlP}^{\mathrm{b}}$ & $\mathrm{FeP}^{\mathrm{b}}$ & Apatite & Lecithin & R-factor \\
\hline \multicolumn{9}{|l|}{ Bulk soils } \\
\hline \multirow[t]{2}{*}{ Lanna 0-10 } & weight (\%) & $55 \pm 1$ & & & & $15 \pm 1$ & $30 \pm 2$ & 0.001 \\
\hline & presence & $1,2,3,4,5$ & 3 & & & $1,2,4,5$ & $1,2,3,4,5$ & \\
\hline \multirow[t]{2}{*}{ Lanna 10-30 } & weight (\%) & $52 \pm 1$ & & & & $16 \pm 1$ & $32 \pm 2$ & 0.002 \\
\hline & presence & $1,2,3,4,5$ & 4 & & & $1,2,3,5$ & $1,2,3,4,5$ & \\
\hline \multirow[t]{2}{*}{ Lanna 30-50 } & weight (\%) & $29 \pm 3$ & $20 \pm 3$ & & & $51 \pm 3$ & & 0.001 \\
\hline & presence & $1,2,3,4,5$ & 1 & & 5 & $1,2,3,4,5$ & & \\
\hline \multirow[t]{2}{*}{ Lanna 50-70 } & weight (\%) & $21 \pm 4$ & & & & $79 \pm 1$ & & 0.001 \\
\hline & presence & $1,2,3,4,5$ & & 2,3 & 4,5 & $1,2,3,4,5$ & & \\
\hline \multirow[t]{2}{*}{ Lanna 70-100 } & weight (\%) & $14 \pm 1$ & & & & $86 \pm 1$ & & 0.002 \\
\hline & presence & $1,2,3,4,5$ & & 3,4 & 5 & $1,2,3,4,5$ & & \\
\hline \multicolumn{9}{|l|}{ Clay fractions } \\
\hline \multirow[t]{2}{*}{ Lanna 0-10 } & weight (\%) & $22 \pm 1$ & & $31 \pm 1$ & & & $46 \pm 1$ & 0.002 \\
\hline & presence & $1,2,3,4$ & 5 & $1,2,5$ & & 3,4 & $1,2,3,4,5$ & \\
\hline \multirow[t]{2}{*}{ Lanna 10-30 } & weight (\%) & $40 \pm 1$ & $24 \pm 6$ & & & & $37 \pm 6$ & 0.002 \\
\hline & presence & $1,2,5$ & $1,2,3,4$ & 4,3 & & 5 & $1,2,3,4,5$ & \\
\hline \multirow[t]{2}{*}{ Lanna 30-50 } & weight (\%) & $28 \pm 6$ & $72 \pm 5$ & & & & & 0.002 \\
\hline & presence & $1,2,3,4,5$ & $1,2,3,4,5$ & 2 & & & 4,5 & \\
\hline \multirow[t]{2}{*}{ Lanna 50-70 } & weight (\%) & $31 \pm 1$ & & & & $69 \pm 1$ & & 0.001 \\
\hline & presence & $1,4,5$ & $2,3,5$ & & & $1,2,3,4$ & & \\
\hline \multirow[t]{2}{*}{ Lanna 70-100 } & weight (\%) & & $16 \pm 2$ & $24 \pm 1$ & & $60 \pm 2$ & & 0.003 \\
\hline & presence & 2,3 & $1,4,5$ & $1,2,3,4$ & & $1,2,3,4,5$ & & \\
\hline
\end{tabular}

${ }^{\mathrm{a}}$ The error estimates of the weights are statistical uncertainties in the linear-combination fitting as reported by Athena (Ravel, 2009), and do not include any variations attributable to background subtraction and normalization.

${ }^{\mathrm{b}} \mathrm{AlP}$ are aluminium phosphates (amorphous $\mathrm{Al}$ phosphate and variscite), whereas FeP are iron(III) phosphates (amorphous Fe(III) phosphate and strengite). 
Table 5: Linear combination fitting results of $\mathrm{P}$ speciation in the bulk soil, with the $\mathrm{P}$ speciation in the clay fraction as a standard. ${ }^{\mathrm{a}}$ The R-factor is the goodness-of-fit parameter reported by Athena. Compounds in the five best fits are numbered in italics from 1 to 5.

\begin{tabular}{|c|c|c|c|c|c|c|c|}
\hline & & $\begin{array}{l}\text { P adsorbed on } \\
\text { Al hydroxide }\end{array}$ & $\begin{array}{l}\text { P adsorbed on } \\
\text { Fe (hydr)oxide }\end{array}$ & $\mathrm{AlP}^{\mathrm{b}} \quad \mathrm{FeP}^{\mathrm{b}}$ & Apatite & $\begin{array}{l}\text { Clay } \\
\text { fraction }\end{array}$ & R-factor \\
\hline \multirow[t]{2}{*}{ Lanna 0-10 } & weight (\%) & $27 \pm 2$ & & & & $73 \pm 3$ & 0.001 \\
\hline & presence & 1,4 & 2,3 & 5 & & $1,2,3,4,5$ & \\
\hline \multirow[t]{2}{*}{ Lanna 10-30 } & weight (\%) & $20 \pm 2$ & & & & $80 \pm 2$ & 0.002 \\
\hline & presence & 1 & 2,3 & 4,5 & & $1,2,3,4,5$ & \\
\hline \multirow[t]{2}{*}{ Lanna 30-50 } & weight (\%) & & & & $57 \pm 1$ & $42 \pm 1$ & 0.002 \\
\hline & presence & & & & $1,2,3,4,5$ & $1,2,3,4,5$ & \\
\hline \multirow[t]{2}{*}{ Lanna 50-70 } & weight (\%) & & & & $45 \pm 3$ & $56 \pm 4$ & 0.003 \\
\hline & presence & & 4 & & $1,2,3,5$ & $1,2,3,4,5$ & \\
\hline \multirow[t]{2}{*}{ Lanna 70-100 } & weight (\%) & & & & $61 \pm 3$ & $39 \pm 3$ & 0.003 \\
\hline & presence & & & & $1,2,3,4,5$ & $1,2,3,4,5$ & \\
\hline
\end{tabular}

${ }^{a}$ The error estimates of the weights are statistical uncertainties reported by Athena (Ravel, 2009), and do not consider errors in background subtraction and normalization.

${ }^{\mathrm{b}} \mathrm{AlP}$ are aluminium phosphates (amorphous $\mathrm{Al}$ phosphate and variscite), whereas FeP are iron(III) phosphates (amorphous Fe(III) phosphate and strengite).

\subsection{Solubility experiments}

At the natural $\mathrm{pH}$ of the soil, dissolved $\mathrm{PO}_{4}-\mathrm{P}$ decreased with depth (Fig. 2). However, when the soil was acidified the dissolved concentration of $\mathrm{P}$ increased in all soils. The minimum concentrations of dissolved $\mathrm{PO}_{4}-\mathrm{P}$ occurred between $\mathrm{pH} 5.5$ and 7, depending on the soil. The dissolved concentrations of $\mathrm{Ca}, \mathrm{Al}$ and $\mathrm{Fe}$ increased with decreasing $\mathrm{pH}$, except for the topsoil in which dissolved $\mathrm{Al}$ and Fe increased at $\mathrm{pH}>5$ for $\mathrm{Fe}$ and $\mathrm{pH}>6$ for $\mathrm{Al}$. This trend could be explained by an increase in dissolved organic matter with Fe(III)- and Al-organic complexes at higher pH (see e.g. Gustafsson and van Schaik, 2003). Speciation modelling with Visual MINTEQ (Gustafsson, 2014) showed that the equilibrated suspensions in the $50-70 \mathrm{~cm}$ and the 70-100 cm samples were slightly supersaturated with respect to hydroxyapatite at the natural $\mathrm{pH}$ ( 7) and when $\mathrm{pH}$ was increased (Fig. 3). For all other samples and conditions, the suspensions were undersaturated. This suggests that apatite is unstable in the samples from the upper $50 \mathrm{~cm}$ of the pedon and thus likely to dissolve. In deeper soil horizons, hydroxyapatite is still stable and may persist. However, neoformation of Ca phosphate is not likely as this normally requires a higher degree of supersaturation (van der Houwen and Valsami-Jones, 2001). 


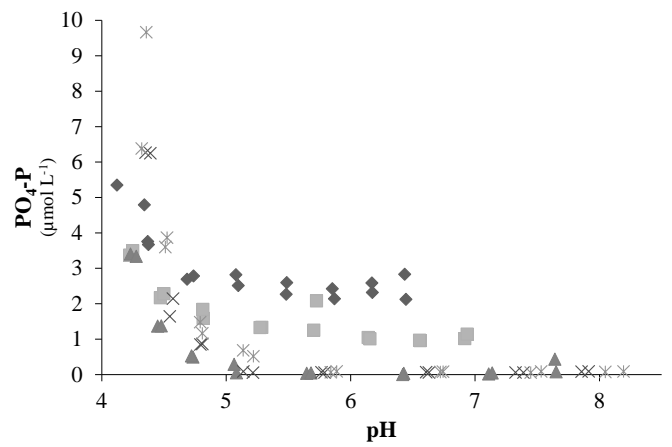

a)

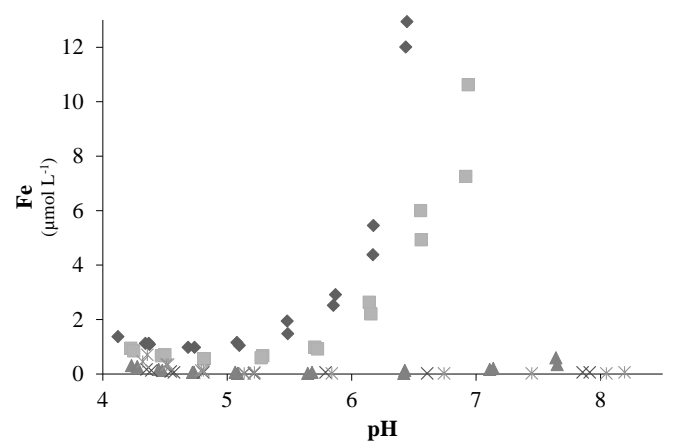

b)
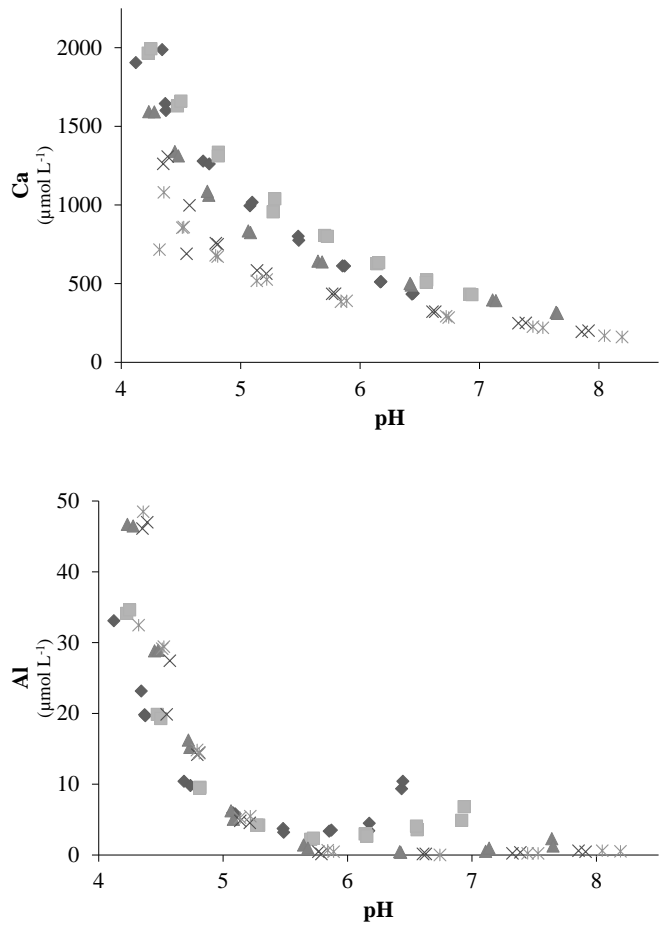

d)

Fig. 2. The $\mathrm{pH}$ depencence of dissolved a) $\mathrm{PO}_{4}-\mathrm{P}$, b) Ca, c) Fe and d) $\mathrm{Al}$ for the different horizons in the soil profile.

\section{Discussion}

This study confirms earlier studies conducted at the Lanna site (Mattson et al., 1950), which showed that the concentration of apatite increased with depth, and that concentrations of other $\mathrm{P}$ species decreased with depth. Similar observations have been made in other studies of soil development, i.e. that the total $\mathrm{P}$ and apatite decreases with time with an increase in concentrations of other P species (Walker and Syers, 1976). This may be a result of weatheringinduced dissolution of apatite, from which the $\mathrm{P}$ can then be transformed to other species, such as P adsorbed on Fe and Al (hydr)oxides, or leached. Two observations from XANES spectroscopy that corroborate the importance of weathering are:

1. The strong vertical gradient of the apatite concentration, i.e. from $15 \%$ concentrations at $0-10 \mathrm{~cm}$ to $86 \%$ of total $\mathrm{P}$ at $70-100 \mathrm{~cm}$. 
2. The finding that apatite was enriched in the bulk soil (Table 5). This probably reflects the fact that fine-grained apatite is likely to dissolve more quickly because of its higher surface area.

Further, the speciation modeling results are in agreement with these conclusions, as they show that hydroxyapatite is thermodynamically unstable in the upper $50 \mathrm{~cm}$ of the pedon. It can be hypothesized that the reason for the low concentrations of apatite in the topsoil is probably due to the progressive acidification, as brought by long-term weathering, plant uptake of cations and accumulation of organic matter. Also at $>50 \mathrm{~cm}$ depth with greater $\mathrm{pH}$, apatite probably dissolves, although more slowly than in the top soil horizons, because the chemical conditions in the deeper horizons do not allow neoformation of Ca phosphate from dissolved P.

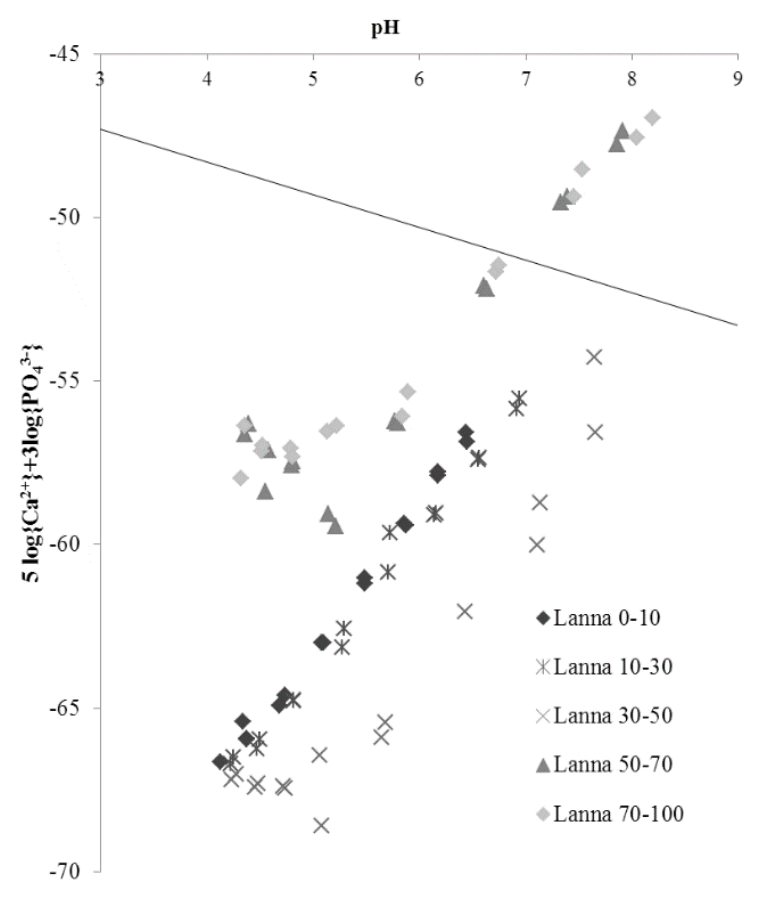

Fig. 3. Stability diagram for the equilibrated suspensions of the $\mathrm{pH}$-dependence experiment. The points represent the calculated solution activities in Visual MINTEQ. The solubility line for hydroxyapatite was calculated from the solubility constant given in Visual MINTEQ $\left(\log * K_{\mathrm{s}}=\right.$ -44.3 at $25^{\circ} \mathrm{C}$ ). Data points above the line indicate supersaturation.

Other minerals are also evidently weathered, e.g. Al- and Fe-containing silicate minerals. Upon dissolution, the released $\mathrm{Al}$ and Fe are likely to form secondary $\mathrm{Al}$ and Fe(III) (hydr)oxide-type 
phases, which may adsorb $\mathrm{PO}_{4}$ (Prietzel et al., 2013). This likely explains the decreasing amount of $\mathrm{PO}_{4}$ adsorbed on $\mathrm{Fe}$ and $\mathrm{Al}$ (hydr)oxides with depth. In the Lanna soil the amount of amphiboles increased slightly with increasing depth. Amphiboles may have been an original host phase for $\mathrm{Al}$ and Fe that was weathered and accumulated as secondary $\mathrm{Al}$ and Fe(III) (hydr)oxides. Also, the relative intensities of the clay peaks in the heated samples suggest they are relatively rich in iron. The vermiculitization observed throughout the profile may also have been a source of iron for the formation of Fe (hydr)oxides (Farmer et al., 1971).

In this study we found, as was previously found for this soil (e.g. Andersson et al., 2015; Andersson et al., 2013; Mattson et al., 1950), a relatively higher concentration of pseudo-total P in the subsoil than in the topsoil. Mattson et al. (1950) hypothesized that this trend was a result of; (1) hundreds of years with pasturing with grass and removal of hay without any amendments of phosphorus to the soil; (2) humus formation; and (3) leaching. This idea requires that the topsoil at some point (e.g. 10000 years ago, after the last glaciation) was chemically similar to the current subsoil. Based on similarities in bulk mineralogy with depth (Table 2), we adopt this weathering model idea in the following discussion. In this context, the results may also be interpreted in the light of the relatively large apatite pool in the subsoil, which contains more P than what is usually retained in soil organic matter or on secondary Fe(III) and Al (hydr)oxides. Thus, the reason for the loss of $\mathrm{P}$ from the topsoil may simply be related to the thermodynamically favorable dissolution of apatite from the topsoil, and to the probability that the long-term steady-state concentration of soil P in the more weathered topsoil is lower than what was present as apatite in the original soil.

XRD analysis identified iron oxides throughout the whole soil profile (Table 2). However, the amount of oxalate-extractable Fe decreased substantially with depth (Table 1). Apparently, the weathering processes in the topsoil converted iron oxides to more reactive forms e.g. ferrihydrite. As pointed out in several reviews (e.g. Borch et al., 2010; Colombo et al., 2014; Zhu et al., 2014) there is a strong relationship between the carbon cycle and the iron cycle in the soil. One reason is that plants can produce organic ligands such as oxalate and citrate that can accelerate the dissolution of soil iron oxides (Colombo et al., 2014; Schwertmann, 1991). Also microbes can accelerate the dissolution of iron oxides in soil by different redox processes (e.g. Borch et al., 
2010; Colombo et al., 2014; Weber et al., 2006). The iron may then be reprecipitated as ferrihydrite having a greater adsorption capacity for phosphate.

We found a strong correlation $\left(\mathrm{r}=0.98^{* * *}\right)$ between the concentration of organic $\mathrm{P}$ and the concentration of organic $\mathrm{C}$ in the Lanna soil, which could be explained by humus formation as discussed by Mattson et al. (1950). This process will form organic acids that will promote dissolution of P-containing compounds and increase P status in the rhizosphere, yields, and amount of organic P (Zhu et al., 2014). According to the XANES results, the organic P was fit with lecithin, a phosphate diester, whereas other studies by ${ }^{31} \mathrm{P}-\mathrm{NMR}$ spectroscopy commonly show that the amount of phosphate diesters is low in Swedish agricultural soil (Ahlgren et al., 2013). However, a well-known problem with solution-phase ${ }^{31}$ P-NMR spectroscopy on alkaline soil extracts is the possibility of diester-P degradation during the extraction, lyophilization, and analysis (e.g. Ahlgren et al., 2013). Phosphate monoesters are commonly the major organic $\mathrm{P}$ species in soils, but the amounts of pyrophosphate, diesters and inositol hexaphosphate may increase with time during soil development (McDowell et al., 2007). On the other hand, as pointed out by Beauchemin et al. (2003) the XANES spectra for organic P species have no distinct features, and thus the organic P species are hard to differentiate and quantify by XANES.

The finding that there was a minimum solubility of $\mathrm{PO}_{4}-\mathrm{P}$ between 5.5 and 7 is consistent with the observations made by Gustafsson et al. (2012) for a larger group of clay soils. The enhanced solubilization of $\mathrm{P}$ at lower $\mathrm{pH}$ may be due to different mechanisms, depending on the soil horizon. In the topsoil, which contained little or no apatite, the increased $\mathrm{PO}_{4}-\mathrm{P}$ may be due to the instability of hydroxy-Al-containing sorbents at low pH, as discussed by Gustafsson et al. (2012). However, in the deeper soil horizons, dissolved $\mathrm{PO}_{4}-\mathrm{P}$ also increased, despite the lower content of $\mathrm{P}$ bound to $\mathrm{Al}$ hydroxide in these horizons. In particular, the 70-100 cm sample showed a very steep increase in $\mathrm{PO}_{4}-\mathrm{P}$ when the $\mathrm{pH}$ was decreased below $\mathrm{pH}$ 5. It is interesting to note that under these conditions, the saturation index relative to hydroxyapatite stabilized at a level of $\sim 10$ orders of magnitudes below the stability line for the three deepest soil samples (Fig. 3). This evidence suggests that apatite dissolution was the main driver of the increased concentration of dissolved $\mathrm{PO}_{4}$-P for these samples. 
Under field conditions, there may be no increased solubilization of $\mathrm{P}$ at low $\mathrm{pH}$ if the acidification occurs very slowly, over pedogenic time scales (thousands of years). A lower $\mathrm{pH}$ will most likely lead to enhanced silicate weathering, which over time may cause an increase of P-sorbing Fe and $\mathrm{Al}$ (hydr)oxides. However, in agricultural soils, significant $\mathrm{pH}$ decreases may occur in just a few decades because of intense management practices (Edmeades and Ridley, 2003), and under such conditions it is less likely that silicate weathering is an important factor for the solubility of $\mathrm{P}$.

Finally, the results confirm that extraction in acid ( $\mathrm{pH}$ 3.75) ammonium lactate will dissolve $\mathrm{P}$ in apatite and gives up to a 50 times higher value than a more alkaline extraction method e.g. Olsen P (Andersson et al., 2015; Andersson et al., 2013).

\section{Conclusions}

The results obtained for the Lanna agricultural clay soil show that:

- In the more weathered topsoil containing more organic matter and poorly crystalline oxides, XANES fitting analysis indicated that $\mathrm{P}$ speciation was dominated by $\mathrm{P}$ adsorbed on an $\mathrm{Al}$-hydroxide phase, with contributions also from organic $\mathrm{P}$ fit as a diester compound.

- In the subsoil, apatite dominates $\mathrm{P}$ speciation, with an additional contribution from $\mathrm{P}$ adsorbed to $\mathrm{Al}$ hydroxide. At 70-100 cm depth, approximately $90 \%$ of total P is apatite.

- Weathering of apatite is an ongoing process in the soil, as indicated by a) the enrichment of apatite in the coarse particle fractions, and by b) the thermodynamic instability of hydroxyapatite as observed for extracts of the topsoil.

- Weathering of amphibole, iron oxides and clay minerals may have caused the accumulation of poorly crystalline iron(III) and aluminum (hydr)oxides in the topsoil, which retain a significant amount of P.

- Acidification of the soil caused increased solubilization of P from all horizons, probably because of two mechanisms: dissolution of hydroxy-Al phases that adsorb P (primarily in the topsoil) and acid-mediated dissolution of apatite (in the subsoil). 


\section{Acknowledgement}

The Swedish Research Council Formas is acknowledged for financial support (contract no. 20101677). This research was partly carried out at SLRI, Thailand. We thank the staff at BL8 for technical support during our beam times. Thanks to David Eveborn for help with the design of the stainless steel holders used at this beam line. We also credit Ian Phillips and Helen Pendlowski at the James Hutton Institute in Aberdeen, Scotland, for help and support during mineralogical analyses. Thanks to the laboratory personnel at the Department of Soil and Environment, SLU; Lena Ek and Roger Lindberg for ICP analyses; Inger Juremalm for extraction of P (P-AL and P-HCl), ICP analyses and measurement of organic C; Christina Öhman for carrying out particle-size distribution analysis. Thanks also to Helena Andersson for providing soil samples.

\section{References}

Ahlgren, J., Djodjic, F., Börjesson, G., Mattsson, L., 2013. Identification and quantification of organic phosphorus forms in soils from fertility experiments. Soil Use Manage. 29, 24-35.

Ajiboye, B., Akinremi, O.O., Jurgensen, A..., 2007. Experimental validation of quantitative XANES analysis for phosphorus speciation. Soil Sci. Soc. Am. J. 71(4), 1288-1291.

Ajiboye, B., Akinremi, O.O., Hu, Y., Jürgensen, A., 2008. XANES speciation of phosphorus in organically amended and fertilized Vertisol and Mollisol. Soil Sci. Soc. Am. J. 72(5), 1256-1262.

Andersson, H., Bergström, L., Djodjic, F., Ulén, B., Kirchmann, H., 2013. Topsoil and subsoil properties influence phosphorus leaching from four agricultural soils. J. Environ. Qual. 42(2), 455-463.

Andersson, H., Bergström, L., Ulén, B., Djodjic, F., Kirchmann, H., 2015. The role of subsoil as a source or sink for phosphorus leaching. J. Environ. Qual. 44(2), 535-544.

Aronsson, H., Stenberg, M., Ulén, B., 2011. Leaching of N, P and glyphosate from two soils after herbicide treatment and incorporation of a ryegrass catch crop. Soil Use Manage. 27(1), 54-68.

Beauchemin, S., Hesterberg, D., Chou, J., Beauchemin, M., Simard, R.R., Sayers, D.E., 2003. Speciation of phosphorus in phosphorus-enriched agricultural soils using X-ray absorption near-edge structure spectroscopy and chemical fractionation. J. Environ. Qual. 32(5), 1809-1819.

Bergström, L., Jarvis, N., Stenström, J., 1994. Pesticide leaching data to validate simulation models for registration purposes. J. Environ. Sci. Health Part A 29(6), 1073-1104.

Bergström, L., Kirchmann, H., Djodjic, F., Kyllmar, K., Ulén, B., Liu, J., Andersson, H., Aronsson, H., Börjesson, G., Kynkänniemi, P., Svanbäck, A., Vila, A., 2015. Turnover and losses of phosphorus in Swedish agricultural soils: long-term changes, leaching trends and mitigation measures. J. Environ. Qual. 44(2), 512523. 
Borch, T., Kretzschmar, R., Kappler, A., van Cappellen, P., Ginder-Vogel, M., Voegelin, A., Campbell, K., 2010.

Biogeochemical redox processes and their impact in contaminant dynamics. Environ. Sci. Technol. 44(1), 15-23.

Bruker, A., 2005. EVA DIFFRAC ${ }^{\text {plus }}$, EVA, Germany.

Colombo, C., Palumbo, G., He, J.-H., Pinton, R., Cesco, S., 2014. Review on iron availability in soil: interaction of Fe minerals, plants, and microbes. J. Soils Sediments 14, 538-548.

Edmeades, D.C., Ridley, A.M., 2003. Using lime to ameliorate topsoil and subsoil acidity. In: Z. Rengel (Ed.), Handbook of soil acidity, pp. 297-336. Marcel Dekker Inc., New York.

Egnér, H., Riehm, H., Domingo, W.R., 1960. Investigations on chemical soil analysis as the basis for estimating the nutrient status of soils. II. Chemical methods of extraction for phosphorus and potassium determinations. Kungliga Lantbrukshogskolans Annaler 26, 199-215.

Eriksson, A.K., Gustafsson, J.P., Hesterberg, D., 2015. Phosphorus speciation of clay fractions from long-term fertility experiments in Sweden. Geoderma 241-242, 68-74.

Eriksson, A.K., 2016. Phosphorus speciation in Swedish agricultural clay soils - Influence of fertilization and mineralogy. PhD Thesis. Acta Universitatis Agriculturae Sueciae - Agraria (2016:25), 72 pp.

Farmer, V.C., Russell, J.D., McHardy, W.J., Newman, A.C.D., Alrichs, J.L., Rimsaite, J.Y.H., 1971. Evidence for loss of protons and octahedral iron from oxidized biotites and vermiculites. Mineral Mag. 38, 121-137.

Franke, R., Hormes, J., 1995. The P K-near edge absorption spectra of phosphates. Physica B 216(1-2), 85-95.

Goldberg, S., Sposito, G., 1984. A chemical-model of phosphate adsorption by soils .1. Reference oxide minerals. Soil Sci. Soc. Am. J. 48(4), 772-778.

Gustafsson, J.P., 2014. Visual MINTEQ, version 3.1. KTH, Royal Institute of Technology. Web: http://vminteq.lwr.kth.se., Stockholm.

Gustafsson, J.P., Mwamila, L.B., Kergoat, K., 2012. The pH dependence of phosphate sorption and desorption in Swedish agricultural soils. Geoderma 189/190, 304-311.

Gustafsson, J.P., van Schaik, J.W.J., 2003. Cation binding in a mor layer: batch experiments and modelling. Eur. J. Soil Sci. 54(2), 295-310.

Hartikainen, H., Simojoki, A., 1997. Changes in soild- and solution-phases phosphorus in soil on acidification. Eur. J. Soil Sci. 48, 493-498.

Hesterberg, D., Zhou, W.Q., Hutchison, K.J., Beauchemin, S., Sayers, D.E., 1999. XAFS study of adsorbed and mineral forms of phosphate. J. Synchrot. Radiat. 6, 636-638.

Hillier, S., 1999. Use of an air brush to spray dry samples for X-ray powder diffraction. Clay Min. 34(1), 127-135.

Hillier, S., 2003. Quantitative analysis of clay and other minerals in sandstones by X-ray powder diffraction (XRPD). Int. Assoc. Sedimentol. Spec. Publ. 34, 213-251.

ISO 11277, 2009. Soil quality -- Determination of particle size distribution in mineral soil material -- Method by sieving and sedimentation.

ISO 11466, 1995. Soil quality - Extraction of trace elements soluble in aqua regia.

Johansson, S., 1944. Soil and water on the Lanna experimental farm. Sveriges Geologiska Undersökningar, Årsbok, 38(3 (461)), pp. 41. Geological Survey of Sweden, Stockholm, -Sweden. 
Karathanasis, A.D., Shumaker, P.D., 2009. Organic and inorganic phosphate interactions with soil hydroxyinterlayered minerals. J. Soils Sediments 9(5), 501-510.

Khare, N., Hesterberg, D., Beauchemin, S., Wang, S.L., 2004. XANES determination of adsorbed phosphate distribution between ferrihydrite and boehmite in mixtures. Soil Sci. Soc. Am. J. 68(2), 460-469.

KLS, 1965. Kungliga Lantbruksstyrelsens kungörelse med bestämmelser för undersökning av jord vid Statens Lantbrukskemiska Kontrollanstalt och Lantbrukskemisk Kontrollstation och Lantbrukskemisk Station med statens fastställda stadgar. (The announcement of the Royal Agriculture Administration for Soil Analysis at the Agricultural Chemistry National Institute and control stations and agricultural stations ruled by governmental regulations.) [in Swedish.]. Kungliga Lantbruksstyrelsen, Stockholm, Sweden.

Klysubun, W., Sombunchoo, P., Deenan, W., Kongmark, C., 2012. Performance and status of beamline BL8 at SLRI for X-ray absorption spectroscopy. J. Synchrotron Radiat. 19, 930-936.

Manning, B.A., Goldberg, S., 1996. Modeling arsenate competitive adsorption on kaolinite, montmorillonite and illite. Clay Clay Min. 44(5), 609-623.

Mattson, S., Williams, E.G., Koutler-Andersson, E., et al., 1950. Phosphate relationships of soil and plant. 5. Forms of P in the Lanna soil. Kungliga Lantbrukshögskolans Annaler 17, 130-140.

McDowell, R.W., Cade-Menun, B., Stewart, I., 2007. Organic phosphorus speciation and pedogenesis: analysis by solution P-31 nuclear magnetic resonance spectroscopy. Eur. J. Soil Sci. 58(6), 1348-1357.

Moore, D.M., Reynolds, R.C., 1997. X-ray diffraction and the identification and analysis of clay minerals. Second edition. Oxford University Press.

Neumann, A., Torstensson, G., Aronsson, H., 2011. Losses of nitrogen and phosphorus via the drainage system from organic crop rotations with and without livestock on a clay soil in southwest Sweden. Organic Agriculture 1(4), 217-229.

Omotoso, O., McCarty, D.K., Hillier, S., Kleeberg, R., 2006. Some successful approaches to quantitative mineral analysis as revealed by the 3rd Reynolds Cup contest. Clays Clay Miner. 54(6), 748-760.

Prietzel, J., Dümig, A., Wu, Y., Zhou, J., Klysubun, W., 2013. Synchrotron-based P K-edge XANES spectroscopy reveals rapid changes of phosphorus speciation in the topsoil of two glacier foreland chronosequences. Geochim. Cosmochim. Acta 108, 154-171.

Ravel, B., Newville, M., 2005. ATHENA, ARTEMIS, HEPHAESTUS: data analysis for X-ray absorption spectroscopy using IFEFFIT. J. Synchrotron Radiat. 12, 537-541.

Ravel, B., 2009. ATHENA User's Guide.

Reynolds, R.C., Jr., 1985. NEWMOD: a computer program for the calculation of one-dimensional diffraction patterns of mixed-layered clays. Hanover, NH, USA.

Schwertmann, U., 1991. Solubility and dissolution of iron oxides. Plant Soil 130, 1-25.

Tannazi, F., Bunker, G., 2005. Determination of chemical speciation by XAFS. Phys. Scripta 115, 953-956.

Ulén, B., Snäll, S. 2007. Forms and retention of phosphorus in an illite clay soil profile with a history of fertilization with pig manure and mineral fertilisers. Geoderma 137, 455-465.

Walker, T.W., Syers, J.K., 1976. Fate of phodphorus during pedogenesis. Geoderma 15(1), 1-19. 
Van der Houwen, J.A.M., Valsami-Jones, E., 2001. The application of calcium phosphate precipitation chemistry to phosphorus recovery: The influence of organic ligands. Environ. Technol. 22(11), 1325-1335.

Van Reeuwijk, L.P., 1995. Procedures for Soil Analyses. International Soil Reference and Information Centre, Wageningen, Netherlands.

Weber, K.A., Achenbach, L.A., Coates, J.D., 2006. Microorganisms pumping iron: anaerobic microbial iron oxidation and reduction. Nature 4, 752-764.

Weng, L.P., Vega, F.A., Van Riemsdijk, W.H., 2011. Competitive and synergistic effects in pH dependent phosphate adsorption in soils: LCD modeling. Environ. Sci. Technol. 45(19), 8420-8428.

Werner, F., Prietzel, J., 2015. Standard protocol and quality assessment of soil phosphorus speciation by P K-edge XANES spectroscopy. Environ. Sci. Technol. 49(17), 10521-10528.

Wolf, A.M., Baker, D.E., 1990. Colorimetric method for phosphorus measurements in amminium oxalate soil extracts. Commun. Soil Sci. Plant Anal. 21(19-20), 2257-2263.

Zhu, Y., Duan, G., Chen, B., Peng, X., Chen, Z., Sun, G., 2014. Mineral weathering and element cycling in soilmicroorganism-plant system. Science China; Earth sciences 57(5), 888-896. 


\section{Evolution of phosphorus speciation with depth in an agricultural soil profile}

Ann Kristin Eriksson ${ }^{\mathrm{a},{ }^{*}}$, Stephen Hillier ${ }^{\mathrm{a}, \mathrm{b}}$, Dean Hesterberg ${ }^{\mathrm{c}}$, Wantana Klysubun ${ }^{\mathrm{d}}$, Barbro

$$
\text { Ulén }^{\mathrm{a}} \text { and Jon Petter Gustafsson }{ }^{\mathrm{a}, \mathrm{e}}
$$

${ }^{a}$ Department of Soil and Environment, Swedish University of Agricultural Sciences, P.O. Box 7014, SE-75007, Uppsala, Sweden.

${ }^{b}$ The James Hutton Institute, Craigiebuckler, Aberdeen, AB15 8QH, United Kingdom

${ }^{c}$ Department of Soil Science, North Carolina State University, Box 7619, Raleigh, NC 27695-7619,

$$
\text { U.S. }
$$

${ }^{d}$ Synchrotron Light Research Institute (SLRI), 111 University Avenue, Muang District, Nakhon Ratchasima 30000, Thailand

${ }^{e}$ Division of Land and Water Resources Engineering, KTH Royal Institute of Technology, Teknikringen 76, 10044 Stockholm, Sweden. 


\section{Content:}

\section{XANES standards.}

Fig. S1: XANES spectra for the standards used for the LCF analyses

Fig. S2: Diffractograms for the synthesised standards used for the LCF analyses of the XANES spectra.

Fig. S3: Diffractograms for the bulk soil mineralogy

Fig. S4: Diffractograms for the air dried clay fractions

Fig. S5: Diffractograms for the glycolated clay fractions

Fig. S6: Diffractograms for the clay fractions heated to $300^{\circ} \mathrm{C}$

Fig. S7: Diffractograms for the K-saturated clay fractions heated to $300^{\circ} \mathrm{C}$

Fig. S8: XANES spectra with LCF fit for the soil samples where the clay fraction was used as a standard

Fig. S9: XANES spectra with LCF fit for the clay fraction samples 


\section{XANES standards}

\section{Preparation of XANES standards}

A set of standards containing minerals, amorphous minerals, $\mathrm{P}$ adsorbed to oxides and organic phosphates were used for the LCF analysis. Four different types of apatite, brushite, monetite, octacalcium phosphate, strengite, struvite and variscite were obtained from the mineral library of the James Hutton Institute and verified by XRD. Hydroxyapatite, octacalcium phosphate, monetite, two types of strengite, $\mathrm{FePO}_{4}$, vivianite, variscite and wavelite were obtained from the mineral library of North Carolina State University. Amorphous minerals were synthesised at the laboratory and verified by XRD. Amorphous calcium phosphate was synthesized according to Eveborn et al. (2009). Amorphous aluminum phosphate and amorphous iron phosphate were synthesized according to Roncal-Herrero et al. (2009). These standards were confirmed to be amorphous by XRD. Standards with adsorbed P were prepared with gibbsite, goethite, amorphous aluminum hydroxide and ferrihydrite. Amorphous aluminum hydroxide was prepared according to Gastuche and Herbillon (1962) and verified by XRD. The sorption experiment was carried out by letting $1 \mathrm{~mL}$ of the prepared suspension $(\sim 0.6 \mathrm{~mol} / \mathrm{L} \mathrm{Al})$ equilibrate with $87 \mathrm{~mL} 2.25 \mu \mathrm{M}$ P with $\mathrm{pH}$ adjusted to 6.5. Ferrihydrite was prepared according to the method of Swedlund and Webster (1999) and Schwertmann and Cornell (2000), according to which $17.92 \mathrm{~mL}$ ferrihydrite suspension ( 36 mmol/L Fe) was equilibrated with $41.3 \mathrm{~mL} 3 \mathrm{mM} \mathrm{NaH}_{2} \mathrm{PO}_{4}$ and $80.78 \mathrm{~mL}$ ultrapure water. The reaction product was verified with XRD to be 2-line ferrihydrite. Phytic acid salts with Na and Ca and lecithin were obtained from Sigma-Aldrich (St. Louis, MI, US).

\section{Collection of standard spectra}

Phosphorus K-edge XANES spectra were collected at beam line BL8 at the Synchrotron Light Research Institute, Nakhon Ratchasima, Thailand. All standards were diluted to have a concentration lower than 800 mmol P kg-1 to avoid self-adsorption (Beauchemin et al., 2003). The samples were mounted on P-free Kapton tape. The beamline was equipped with an InSb (111) crystal monochromator and the flux was $1.3 \times 10^{9}$ to $6 \times 10^{10}$ photons s ${ }^{-1}$. The size of the beam was approximately 12.5 x $0.9 \mathrm{~mm}$ in transmission mode. Data were collected using a solid state 13-element Ge detector fluorescence detector. The energy was calibrated from phosphorus powder to $2145.8 \mathrm{eV}$. Each XANES spectrum was recorded within the energy range of 2100 to $2320 \mathrm{eV}$. The step size varied and was $2 \mathrm{eV}$ between 2100 and $2132 \mathrm{eV}, 1$ $\mathrm{eV}$ between 2132 and $2144 \mathrm{eV}, 0.2 \mathrm{eV}$ between 2144 and $2153 \mathrm{eV}, 0.3 \mathrm{eV}$ between 2153 and 
$2182 \mathrm{eV}$, and $5 \mathrm{eV}$ between 2182 and $2320 \mathrm{eV}$. All measurements were recorded during $3 \mathrm{~s}$. The sample compartment was filled with He gas during data collection.

Data treatment of standards

All standard were background-adjusted with a linear function between $-30 \mathrm{eV}$ and $-10 \mathrm{eV}$ relative to $\mathrm{E}_{0}$ and normalised using a linear function in the post-edge region from $+30 \mathrm{eV}$ to $+45 \mathrm{eV}$ relative to $\mathrm{E}_{0}$. 


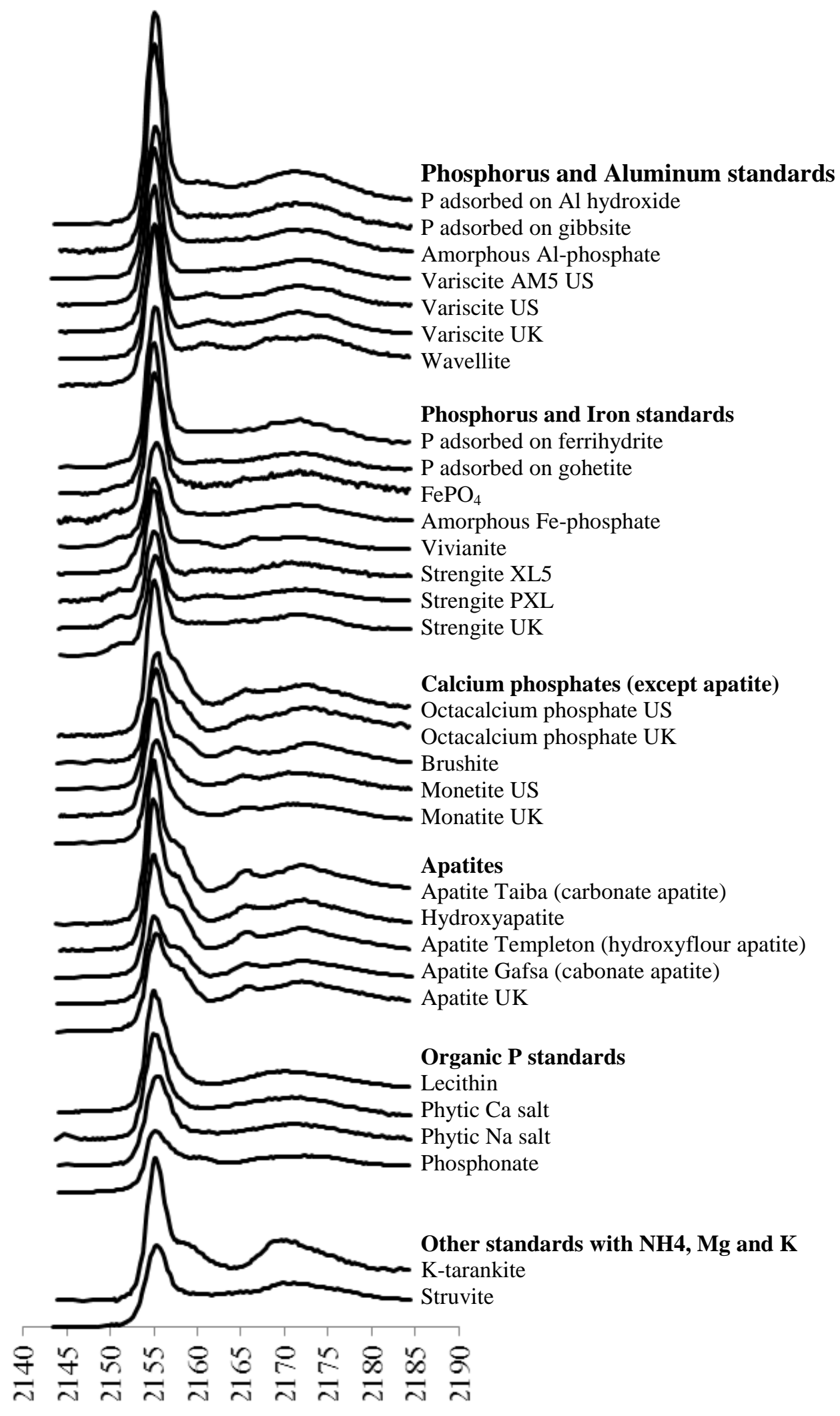

Fig. S1: XANES spectra for the standards used for the LCF analyses of the soil and clay fraction samples. 


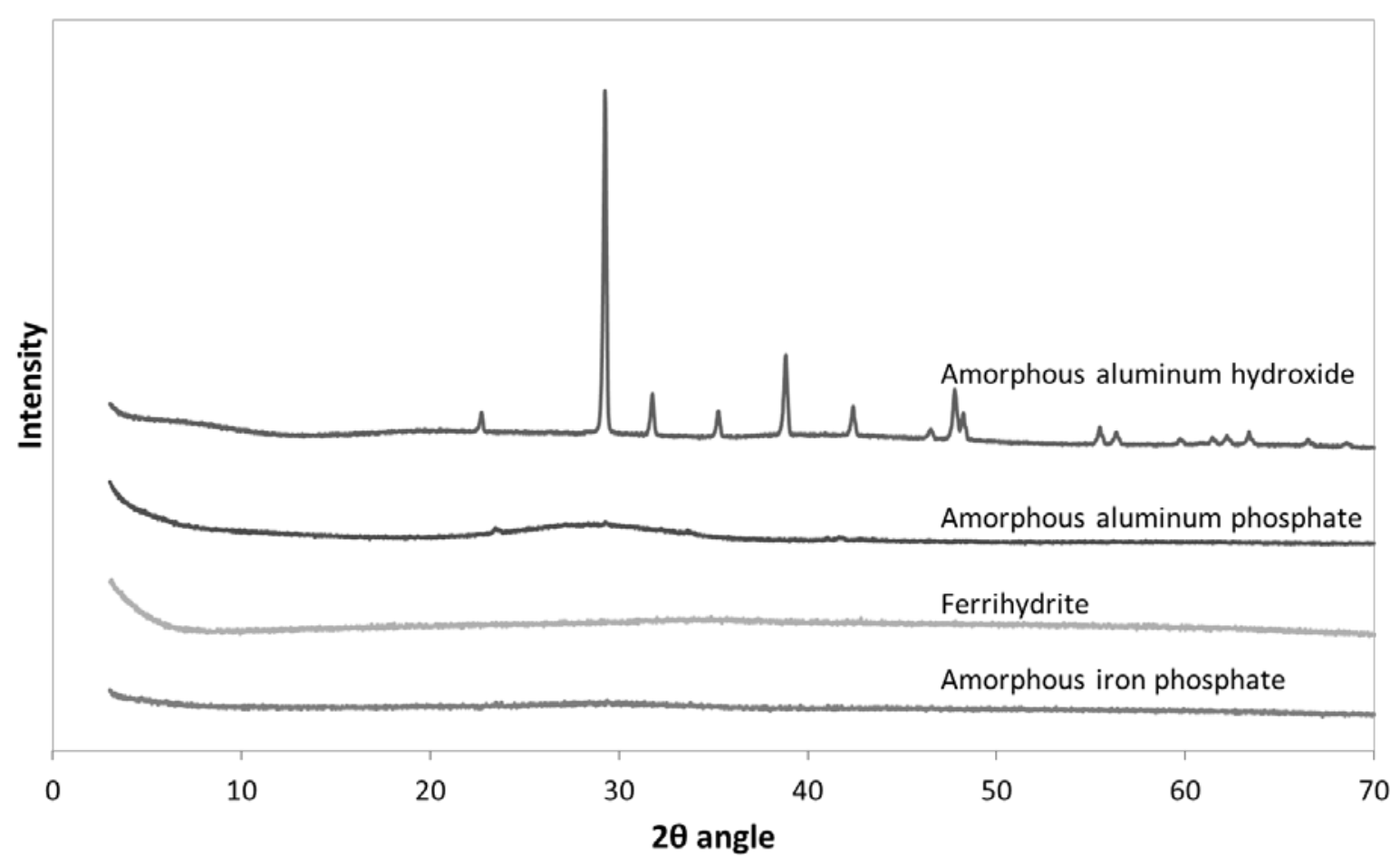

Fig. S2: Diffractograms for the synthesized standards used for the LCF analyses of the XANES spectra. The peaks observed in the amorphous aluminum phosphate originate from a contamination of crystalline $\mathrm{KNO}_{3}$ and in amorphous aluminum hydroxide from crystalline $\mathrm{NaNO}_{3}$. 


\section{Bulk soil}

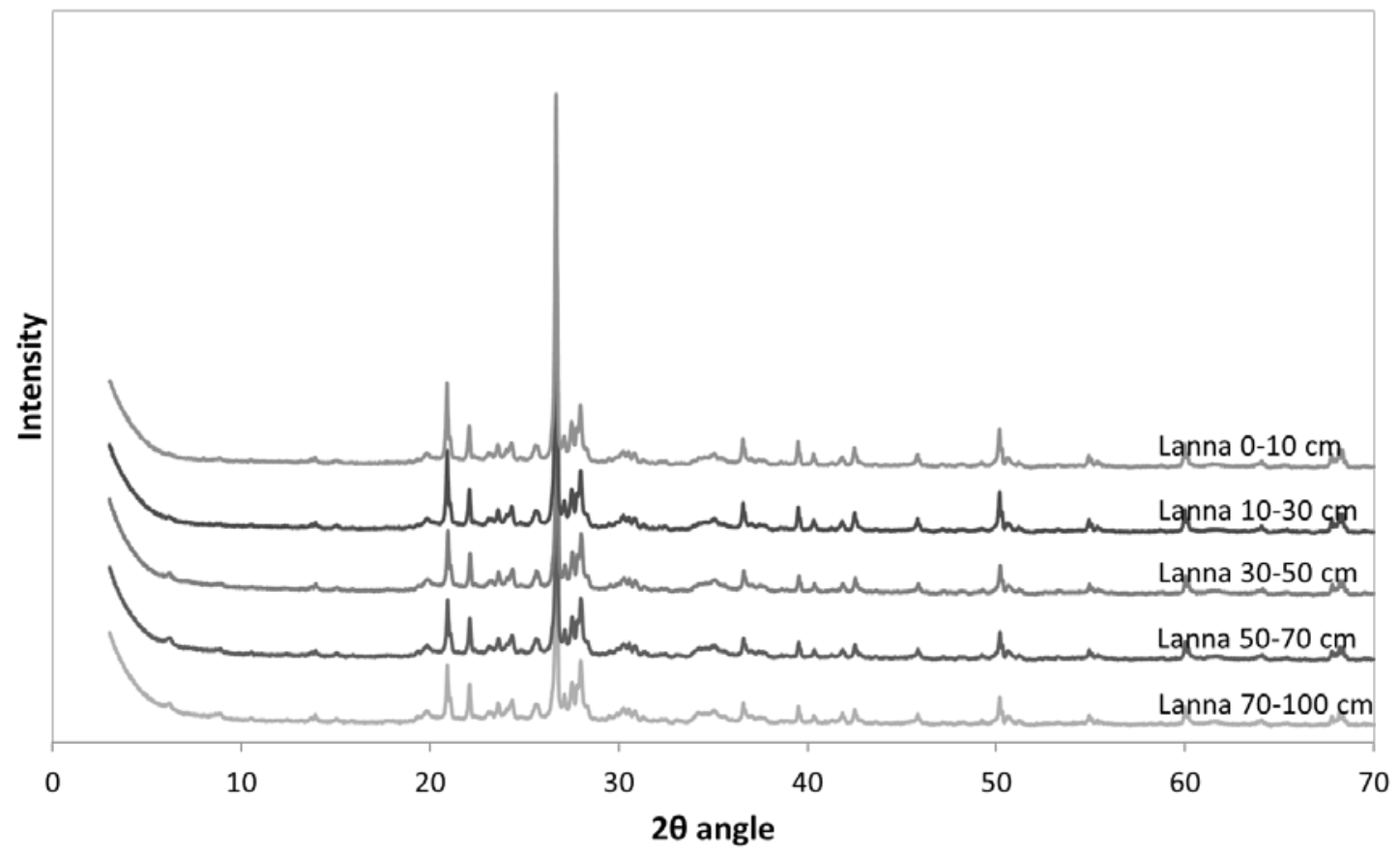

Fig S3: Diffractogram for the bulk soil mineralogy from the different horizons in the soil profile. 


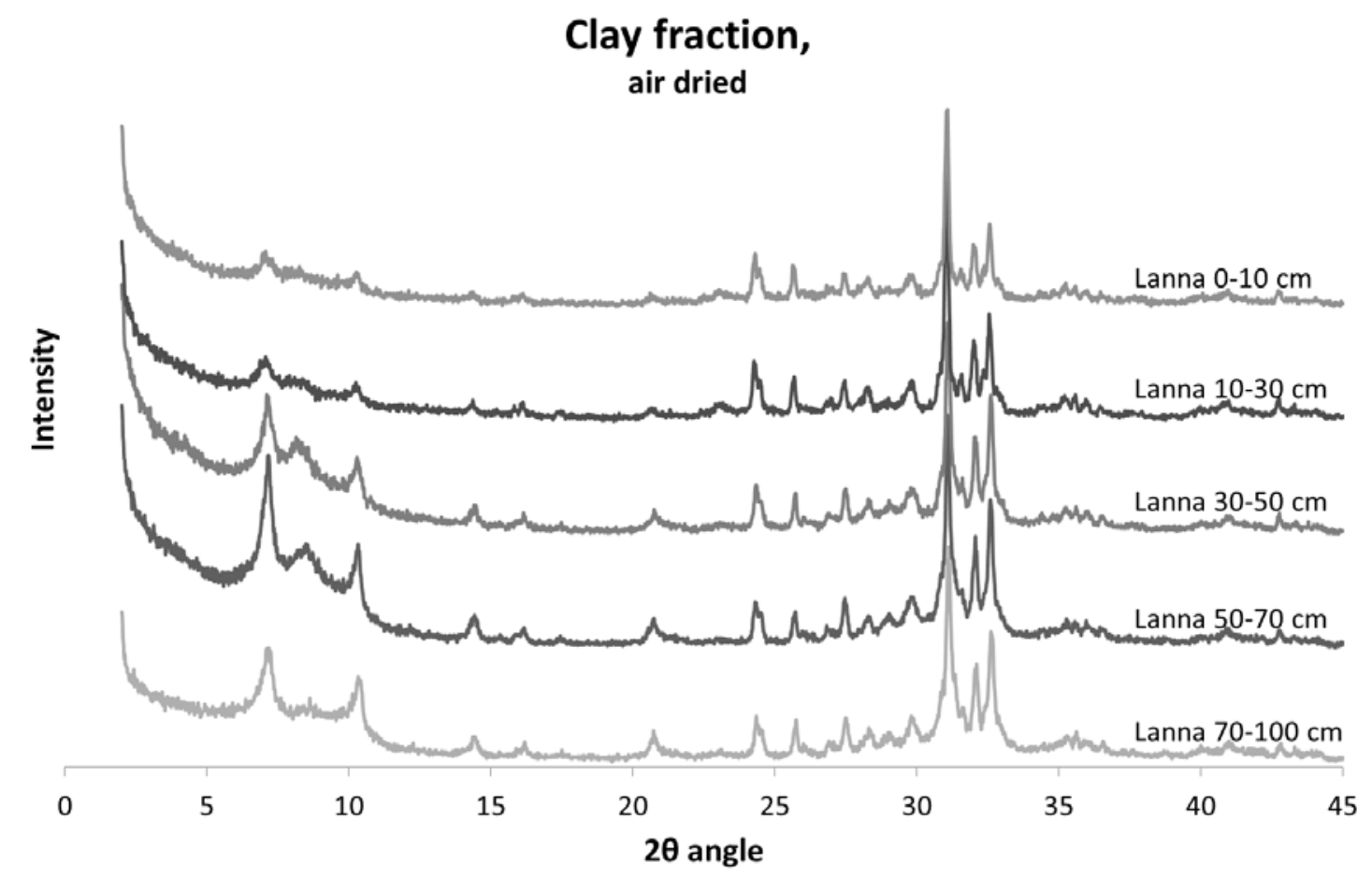

Fig S4: Diffractograms for the air dried clay fractions from the different horizons in the soil profile. 


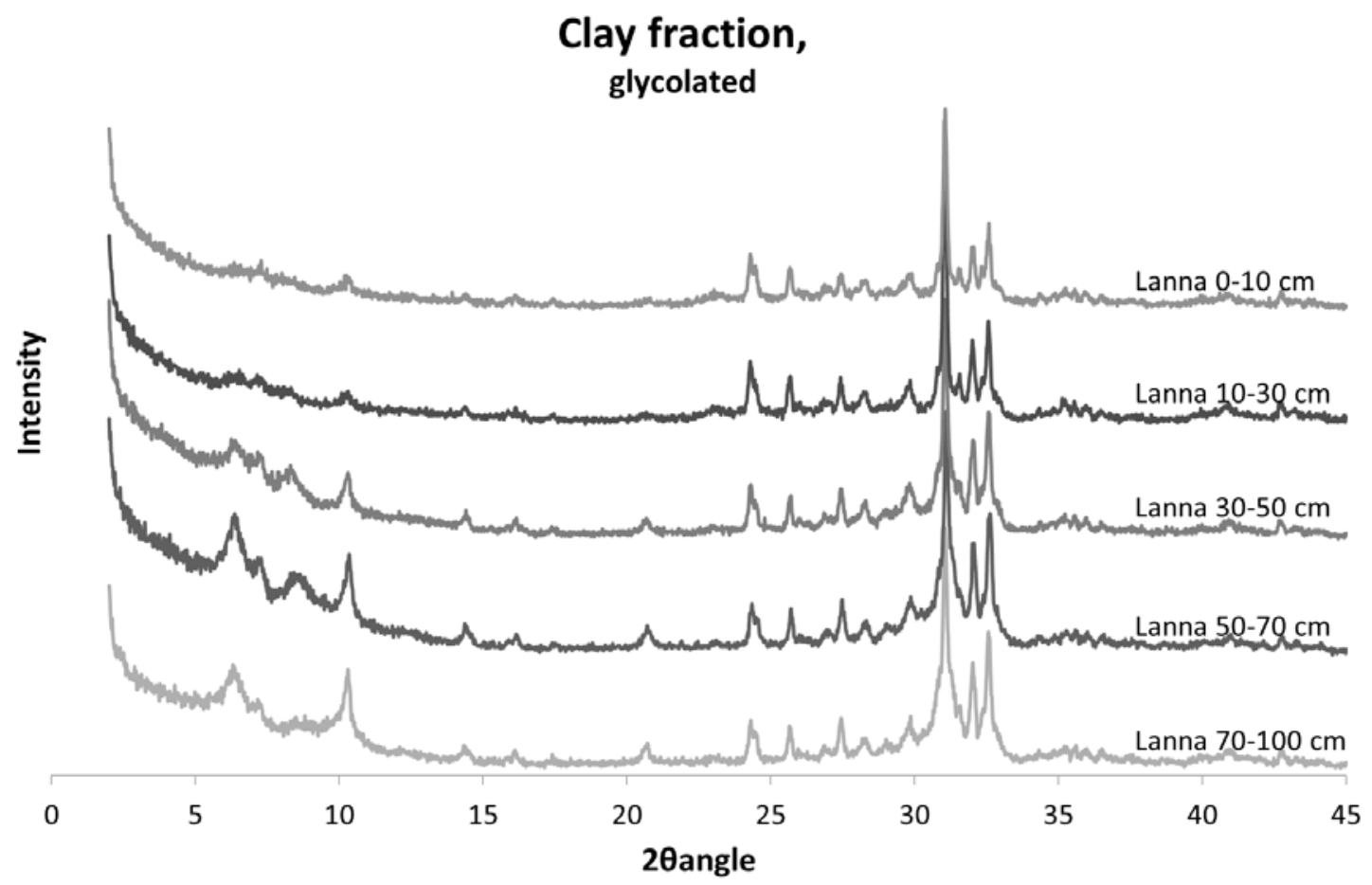

Fig. S5: Diffractograms for the glycolated clay fractions from the different horizons in the soil profile. 


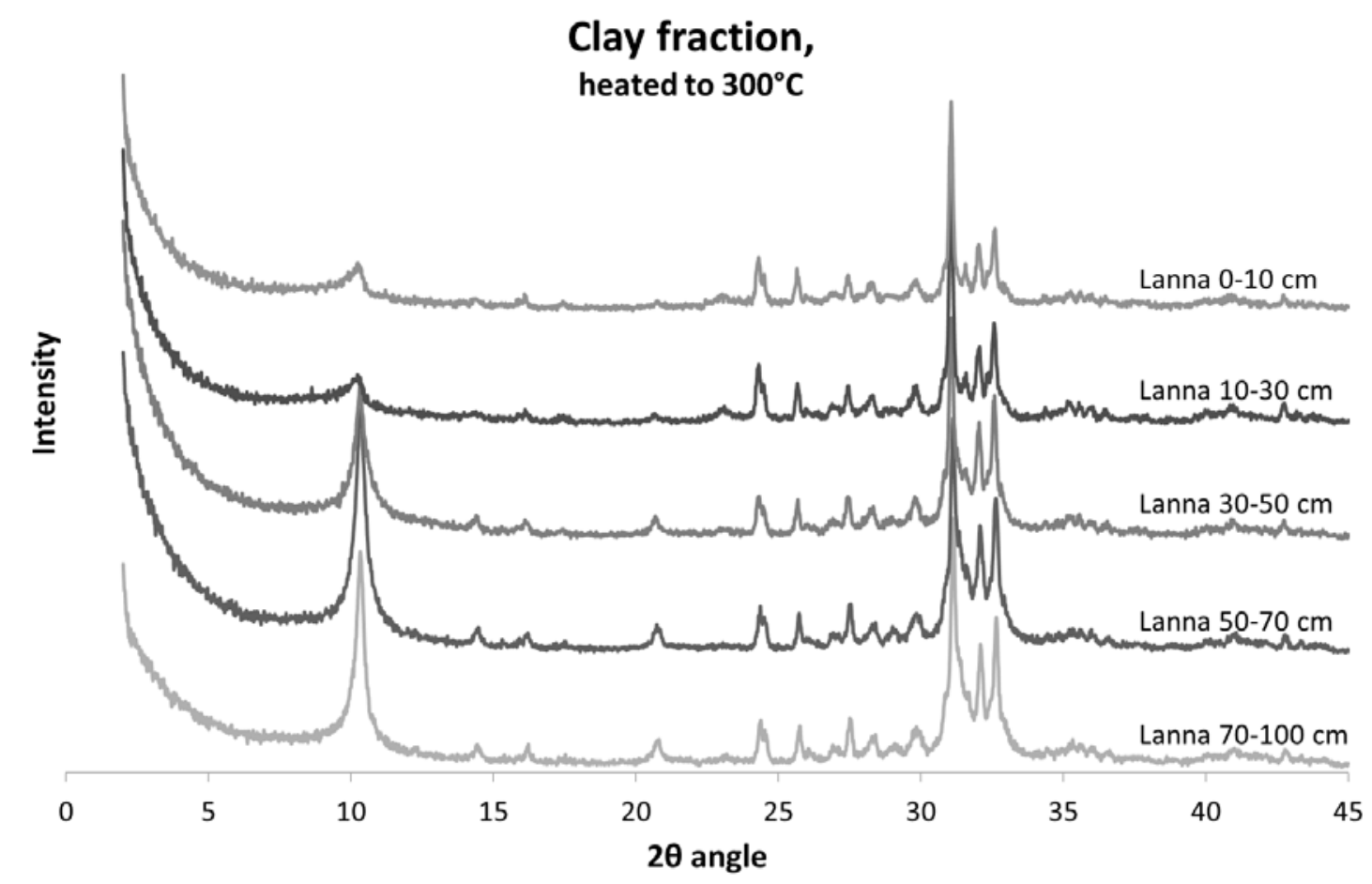

Fig. S6: Diffractograms for the clay fractions heated to $300^{\circ} \mathrm{C}$ from the different horizons in the soil profile. 


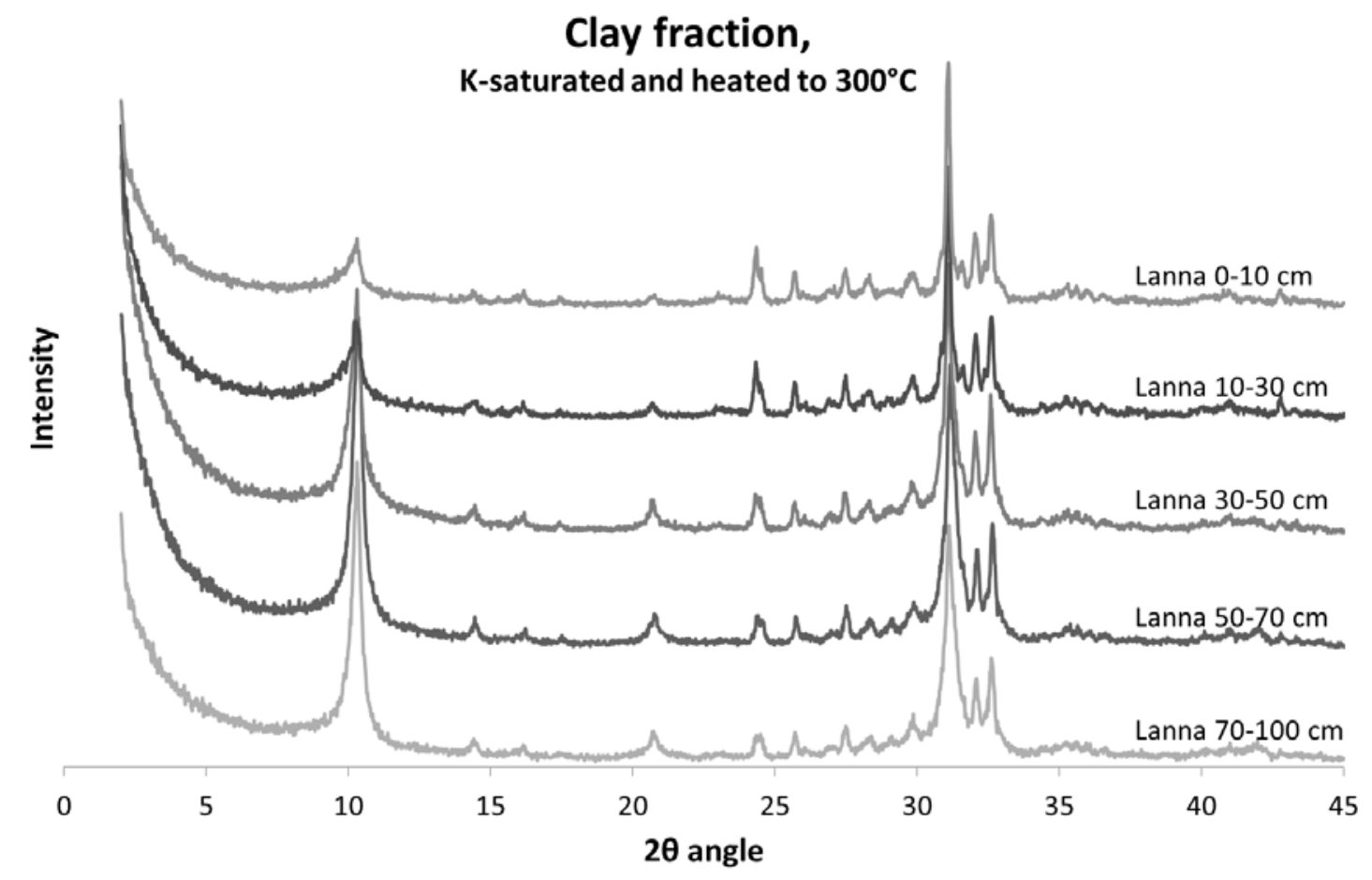

Fig. S7: Diffractograms for the K-saturated clay fractions heated to $300^{\circ} \mathrm{C}$ from the different horizons in the soil profile. 
a)

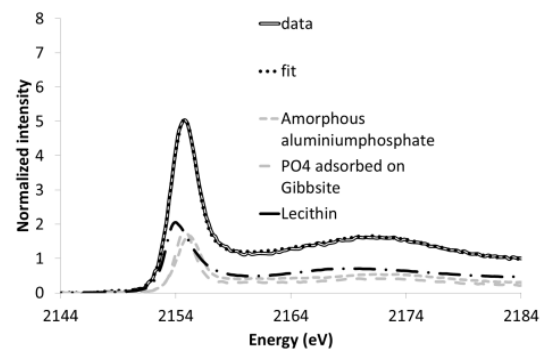

b)

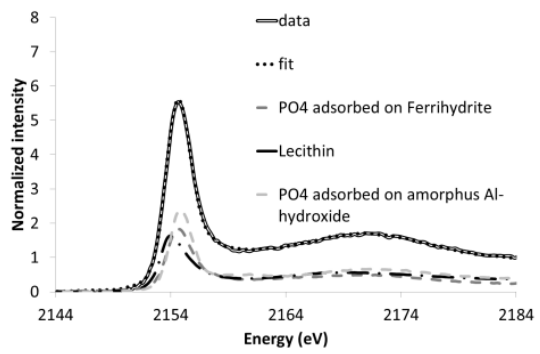

c)

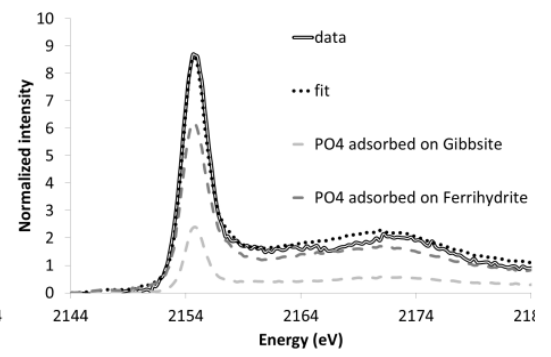

d)

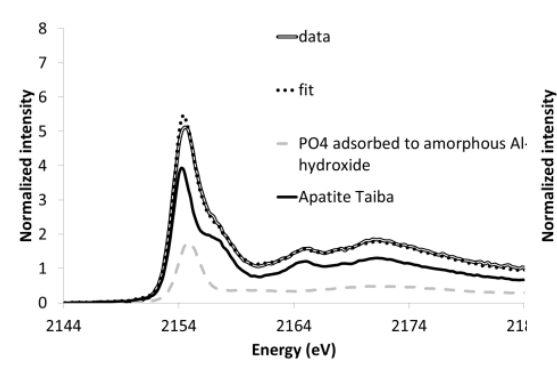

e)

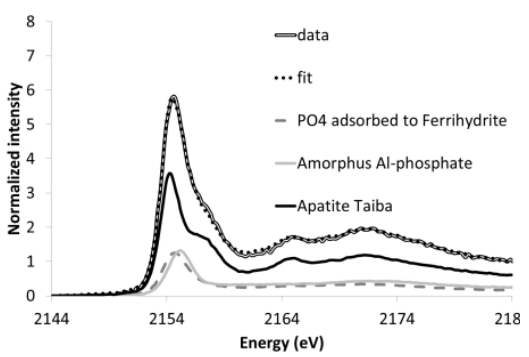

Fig. S8: XANES spectra with LCF fit for the clay fraction samples for a) Lanna 0-10 cm b) Lanna 10-30 cm c) Lanna 30-50cm d) Lanna 50-70 cm and e) Lanna 70-100 cm. 
a)

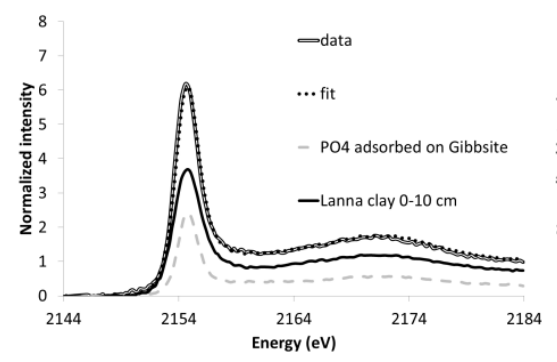

b)

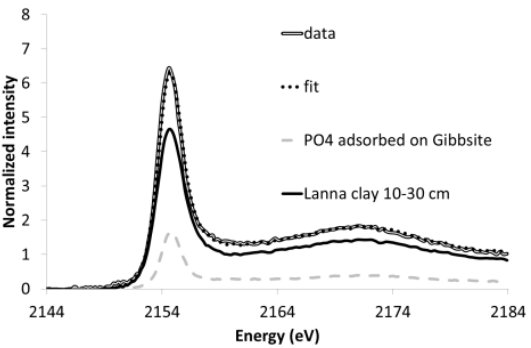

c)

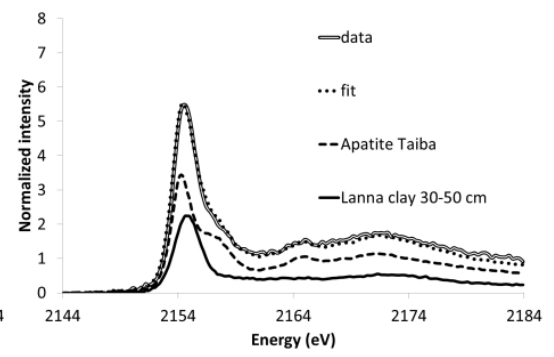

d)

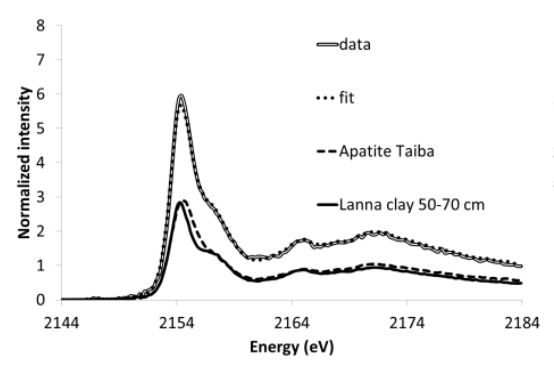

e)

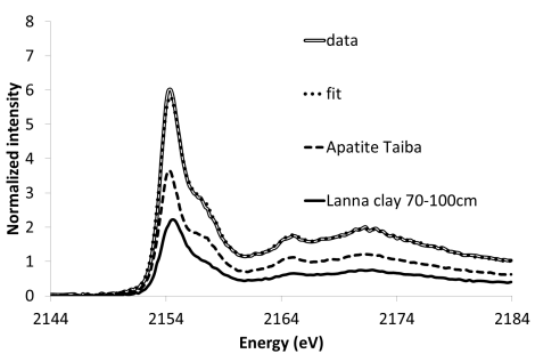

Fig. S9: XANES spectra with LCF fit for the bulk soil with clay fraction samples as a standard a) Lanna 0-10 cm b) Lanna 10-30 cm c) Lanna 30-50cm d) Lanna 50-70 cm and e) Lanna $70-100 \mathrm{~cm}$. 


\section{References}

Beauchemin, S., Hesterberg, D., Chou, J., Beauchemin, M., Simard, R.R., Sayers, D.E., 2003. Speciation of phosphorus in phosphorus-enriched agricultural soils using X-ray absorption near-edge structure spectroscopy and chemical fractionation. J. Environ. Qual. 32(5), 1809-1819.

Eveborn, D., Gustafsson, J.P., Hesterberg, D., Hillier, S., 2009. XANES Speciation of P in Environmental Samples: An Assessment of Filter Media for on-Site Wastewater Treatment. Environ. Sci. Technol. 43(17), 6515-6521.

Gastuche, M.C., Herbillon, A., 1962. Etude des gels d'alumine: Cristallisation en milieu desionise. Bull. Soc. Chim. Fr. (7), 1404-1412

Roncal-Herrero, T., Rodriguez-Blanco, J.D., Benning, L.G., Oelkers, E.H., 2009.

Precipitation of Iron and Aluminum Phosphates Directly from Aqueous Solution as a Function of Temperature from 50 to 200 degrees C. Cryst. Growth Des. 9(12), 51975205.

Schwertmann, U., Cornell, R.M., 2000. Iron oxides in the laboratory: preparation and characterization. Iron oxides in the laboratory: preparation and characterization. WILEY-VCH Verlag GMBH \& Co. KGaA, Weinheim, Germany.

Swedlund, P.J., Webster, J.G., 1999. Adsorption and polymerisation of silicic acid on ferrihydrite, and its effect on arsenic adsorption. Water Res. 33(16), 3413-3422. 